\title{
Evaluation of Events of Extreme Temperature Change between Neighboring Days in CMIP6 Models over China
}

\section{Shuaifeng Song}

Faculty of Geographical Science, Beijing Normal University

Xiaodong Yan ( $\nabla$ yxd@bnu.edu.cn )

Beijing Normal University

\section{Research Article}

Keywords: ETCN, CMIP6 Models, Multi-model Ensembles, China

Posted Date: June 28th, 2021

DOI: https://doi.org/10.21203/rs.3.rs-601223/v1

License: (c) (i) This work is licensed under a Creative Commons Attribution 4.0 International License.

Read Full License 


\title{
Evaluation of Events of Extreme Temperature Change between Neighboring Days in CMIP6
}

\section{Models over China}

\author{
Shuaifeng Song ${ }^{1}$, Xiaodong Yan ${ }^{1 \mathrm{a}}$ \\ 1 State Key Laboratory of Earth Surface Processes and Resource Ecology, Faculty of Geographical \\ Science, Beijing Normal University, Beijing 100875, China
}

\section{Abstract}

In the context of global warming, the frequency and intensity of extreme weather and climate events are increasing. However, the impact of these changes that is directly felt by people is the day-to-day temperature change. Extreme temperature changes between neighboring days (ETCNs) carry substantial disease risks and socioeconomic impacts. Evaluative studies of ETCN events with global circulation models (GCMs) remain unknown in China. This study quantitatively evaluates the performances of $36 \mathrm{GCMs}$ and the multi-model ensemble (MME) of the Coupled Model Intercomparison Project 6 (CMIP6) in simulating the extreme cooling (EC) and extreme warming (EW) events of two consecutive days as defined by relative thresholds. Moreover, we select the optimal models in different regions at the seasonal and annual scales in China, providing theoretical support for the frequency projection and modeling improvement of ETCN events. The results showed that from 1981 to 2013, the annual average EW events and EC events in China showed increasing but not statistically significant trends, and the frequency of EW events was higher than that of EC events. EW events mostly occurred in spring, while EC events mostly occurred in autumn. Additionally, the performances of the CMIP6 models are quite different between EC and EW events. The simulations of EC events are generally more reliable than those of EW events, and the models can also capture the annual cycle of EC events well. Furthermore, the CMIP6 models overestimate the frequencies of EW and EC events but underestimate the frequency of EC events in autumn. The CMIP6 models exhibit poor performance in simulating the trend of and interannual variability in ETCN events and can only simulate the decreasing trend in autumn. Finally, according to the overall ranking of the CMIP6 models, GFDL-ESSM4 and EC-Earth3-Veg-LR achieve the best performance in simulating EW and EC events, respectively. The CMIP6 MME only effectively improved the capabilities of the models to simulate winter EC events in the WNW region. In terms of the trend of and interannual variability in ETCN events, individual models exhibited better performances than the CMIP6 ensemble.

Keywords: ETCN, CMIP6 Models, Multi-model Ensembles, China

a Corresponding author: Xiaodong Yan, PhD and Professor, E-mail address: yxd@bnu.edu.cn. 


\section{Introduction}

Global climate change is a great challenge for humankind. According to the fifth assessment report of the IPCC, from 1880 to 2012, the global average surface temperature showed an upward linear trend, increasing by $0.85^{\circ} \mathrm{C}$ (IPCC, 2013). Compared with the mean climate state, extreme weather and climate events are more sensitive to global warming (Aguilar et al. 2009; Ha and Yun 2012; Schoetter et al. 2015; Lewis et al. 2017), and their frequency and intensity are also increasing (Sui et al. 2018), exerting profound impacts on ecosystems and human society (Easterling et al. 2000). The day-to-day temperature changes and fluctuations induced by climate change are directly felt by people ( $\mathrm{Li}$ and Yan 2010). An extreme temperature change between neighboring days (ETCN) refers to a dramatic change between the daily average temperature of a given day and the temperature of the previous day. Recent studies found that ETCN changes not only have huge effects on ecosystems but also increase the risk of disease and death. These impacts indicate that in addition to the commonly used temperature indicators (such as the average temperature, maximum temperature, and minimum temperature), ETCN is an important meteorological index that reflects the impacts of meteorological environmental changes and human health-related changes (Goldberg et al. 2011; Zhan et al. 2017).

In recent years, the frequency, intensity, and duration of ETCNs have increased (Xu et al. 2015), increasing the risk of disease and death (Lin et al. 2013; Cheng et al. 2014). For example, Guo et al. (2011) showed that when the 24-hour temperature decreased by $3{ }^{\circ} \mathrm{C}$ in Brisbane, the nonaccidental death rate increased by $15.7 \%$, the cardiovascular death rate increased by $35.3 \%$, and people under the age of 65 were most easily affected. Kang et al. (2021) also found that for a $1{ }^{\circ} \mathrm{C}$ increase in temperature variability, a $6 \%$ increase was observed in cardiovascular disease in China. More studies have found that changes in ETCNs are related to infectious diseases, such as hand, foot, and mouth disease (Xu et al. 2015; Cheng et al. 2016), pneumonia (Xu et al. 2014), and respiratory tract infections (Liu et al. 2015). In addition, ETCNs also affect the growth and reproduction of animals and plants. In Australia, studies on lizards have shown that sharp temperature fluctuations can change the shape of lizards and have a significant effect on embryo formation (Shine and Elphick 2001). Overall, China has a large population and a complex and diverse climate and is especially vulnerable to extreme weather events, resulting in serious economic losses and casualties. Given these characteristics, quantitatively evaluating the performances of CMIP6 models in simulating ETCNs is essential for enhancing our confidence in reducing model uncertainties and developing adaptation strategies to reduce the risk of diseases, especially in different regions and seasons in China (Ren et al. 2011). Given these aims, quantitative indicators must be established to measure the performance of models in simulating 
ETCN events.

Global climate models are important tools used for climate simulations and projections of future climate change (Yang et al. 2018). The Coupled Model Intercomparison Project (CMIP) launched by the World Climate Research Program (WCRP) has evolved through CMIP1 (1995), CMIP2 (1997), CMIP3 (2004), and CMIP5 (2013) since its inception. Today, the Coupled Model Intercomparison Project (CMIP) has entered the CMIP6 phase, with CMIP6 providing data on the current simulations and future projections of approximately 112 climate models from nearly 33 institutions around the world (Zhou et al. 2019); these models will be used for the preparation of the IPCC's sixth assessment report. Compared with the previous-generation CMIP5 model, CMIP6 is significantly improved in its spatial resolution, physical process, coupled carbon cycle, and so on (Eyring et al. 2016). The ability of a model to simulate the current climate has a direct impact on the accuracy of its future projections. Therefore, it is necessary to test the simulation ability of models and to objectively evaluate the accuracy and uncertainty of the simulation results (Grose et al. 2020). Many scholars have evaluated the ability of CMIP6 models to simulate air temperature (Luo et al. 2020), extreme precipitation (Akinsanola et al. 2020), terrestrial evapotranspiration (Wang et al. 2020), sea ice (Notz and Community 2020), the Hadley circulation (Grise and Davis 2020), soil moisture (Yuan et al. 2021), wind speed (Krishnan and Bhaskaran 2020), snow depth (Chen et al. 2021), the Indian Ocean dipole (McKenna et al. 2020), the East Asian summer monsoon index (Xin et al. 2020), and so on. Regarding ETCNs, Peng et al. (2019) used daily temperature data from 804 meteorological stations across China to calculate the frequency of consecutive days with temperature differences greater than $1{ }^{\circ} \mathrm{C}$. However, the temperature change threshold set by the author was too small to reflect extreme situations of temperature changes between neighboring days. Zhou et al. (2020) studied the spatiotemporal pattern of global day-to-day temperature changes using station-collected data and 27 CMIP6 models. The results showed that events in which the daily average temperature decreased by more than $10{ }^{\circ} \mathrm{C}$ decreased. However, the author only studied the trend changes of EC events and did not consider changes in EW events or seasonal changes. At the beginning of the 21st century, the World Meteorological Organization (WMO) and WCRP jointly established the Expert Team on Climate Change Detection and Indexes (ETCCDI). According to daily temperature and precipitation data, the ETCCDI defined 27 representative extreme climate indexes for the study of global and regional extreme climate change (Kim et al. 2020; Akinsanola et al. 2020; Ge et al. 2021; Fan et al. 2020); the ETCN index was not defined.

Therefore, research on the evaluation of different meteorological elements or variables in China using CMIP6 models has been extensive, but to our knowledge, few relevant evaluative studies of ETCN events using CMIP6 models have been conducted in different seasons over China. 
To what extent do CMIP6 models capture the annual cycle, spatial pattern, trend change, and temporal variability of ETCN events? Which models should be selected as the optimal models based on a set of metrics in different zones in China? Is the performance of MME better than that of individual models? Motivated by these questions, the purpose of this study is to quantitatively evaluate the performance of individual CMIP6 models and the multimodel ensemble in simulating ETCN events, which are defined by relative thresholds and divided into EC events and EW events in eight subreigons in China. In addition, the possible causes of the models' biases are discussed. This study provides a reliable scientific theory for the improvement of climate models and the projection of future EW and EC events in China.

\section{Data and methods}

\subsection{Data}

As a reference from observations, we used the daily average temperature data provided by the National Climate Center of the China Meteorological Administration. This dataset has been widely used in research on climate change in China. The research period of this study is from January 1, 1981, to February 28, 2014. To better evaluate the ability of the models to simulate the ETCN event frequencies in different regions of China, China was divided into eight regions in this paper. These subregions over land were adapted from Wu et al. (2020) as shown in Fig. 1.

GCM daily mean temperature data were downloaded from the CMIP6 dataset (https://esgfnode.llnl.gov/search/cmip6/). The dataset covers the same period as the observations. We chose the "Experiment ID" as the "historical" term and the "Variant Label" as the "r1i1p1f1" term, for a total of 36 models. Table 1 provides an overview of the institutions, model names, and resolution information.

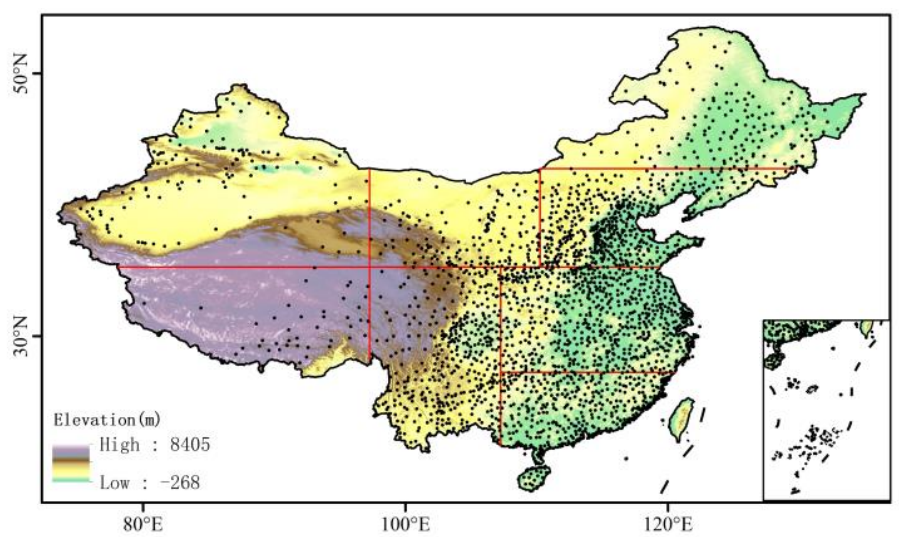

Fig. 1 Spatial distribution of the 2298 stations and elevation of the topography over mainland China. The red solid lines and numbers indicate the eight subregions: (1) Northeast China (NEC), (2) North China (NC), (3) West 
Table 1 Information on the CMIP6 models used in this study

\begin{tabular}{|c|c|c|c|c|c|c|c|}
\hline & Model name & Resolution & Source & & Model name & Resolution & Source \\
\hline 1 & ACCESS-CM2 & $192 \times 144$ & CSIRO-ARCCSS-BoM & 19 & GFDL-CM4 & $288 \times 180$ & NOAA-GFDL \\
\hline 2 & ACCESS-ESM1-5 & $192 \times 145$ & CSIRO & 20 & GFDL-ESM4 & $288 \times 180$ & NOAA-GFDL \\
\hline 3 & AWI-CM-1-1-MR & $384 \times 192$ & AWI & 21 & IITM-ESM & $192 \times 94$ & CCCR-IITM \\
\hline 4 & AWI-ESM-1-1-LR & $192 \times 96$ & AWI & 22 & INM-CM4-8 & $180 \times 120$ & INM \\
\hline 5 & BCC-CSM2-MR & $320 \times 160$ & $\mathrm{BCC}$ & 23 & INM-CM5-0 & $540 \times 360$ & INM \\
\hline 6 & BCC-ESM1 & $128 \times 64$ & $\mathrm{BCC}$ & 24 & IPSL-CM6A-LR & $144 \times 143$ & IPSL \\
\hline 7 & CanESM5 & $128 \times 64$ & CCCma & 25 & KIOST-ESM & $192 \times 96$ & KIOST \\
\hline 8 & CESM2-FV2 & $144 \times 96$ & NCAR & 26 & MIROC6 & $256 \times 128$ & MIROC \\
\hline 9 & CESM2 & $288 \times 192$ & NCAR & 27 & MPI-ESM1-2-HR & $384 \times 192$ & MPI-M \\
\hline 10 & CESM2-WACCM-FV2 & 144 x 96 & NCAR & 28 & MPI-ESM1-2-LR & $192 \times 96$ & MPI-M \\
\hline 11 & CESM2-WACCM & $288 \times 192$ & NCAR & 39 & MPI-ESM-1-2-HAM & $192 \times 96$ & HAMMOZ-Consortium \\
\hline 12 & CMCC-CM2-HR4 & $288 \times 192$ & $\mathrm{CMCC}$ & 30 & MRI-ESM2-0 & $320 \times 160$ & MRI \\
\hline 13 & CMCC-CM2-SR5 & $288 \times 192$ & CMCC & 31 & NESM3 & $192 \times 96$ & NUIST \\
\hline 14 & EC-Earth3 & $512 \times 256$ & EC-Earth-Consortium & 32 & NorCPM1 & $144 \times 96$ & $\mathrm{NCC}$ \\
\hline 15 & EC-Earth3-Veg & $512 \times 256$ & EC-Earth-Consortium & 33 & NorESM2-LM & $144 \times 96$ & $\mathrm{NCC}$ \\
\hline 16 & EC-Earth3-Veg-LR & $320 \times 160$ & EC-Earth-Consortium & 34 & NorESM2-MM & $288 \times 192$ & $\mathrm{NCC}$ \\
\hline 17 & FGOALS-f3-L & $360 \times 180$ & CAS & 35 & SAM0-UNICON & $288 \times 192$ & SNU \\
\hline 18 & FGOALS-g3 & $180 \times 80$ & CAS & 36 & TaiESM1 & $360 \times 180$ & AS-RCEC \\
\hline
\end{tabular}

2.2 Extreme temperature change between neighboring day event index definitions and calculations

A day-to-day temperature change is estimated as the difference between the daily average temperatures on two neighboring days (Gough, 2008; Zhan et al. 2017; Lei et al. 2020):

$$
T C N=T_{i}-T_{i-1} \quad(i=1,2,3 \ldots n)
$$

where TCN denotes a change in the average daily temperature for day $i$ and $T_{i}\left(T_{i-1}\right)$ denotes the average daily temperature for day $i$ (the previous day is denoted as $i-1$ ). The term

$141 n$ is the total number of days in the four seasons, which are spring (MAM), summer (JJA), autumn

142 (SON), and winter (DJF). TCN $<0$ indicates a cooling event, while TCN $>0$ indicates a warming 143 event. 
Slight warming or cooling events have little impact on human health. Thus, this study only considers the occurrence of sudden strong warming or cooling events. Using the top and bottom tenth percentiles as the criteria (Shi et al. 2018; Tan et al. 2021), the 10th percentile and 90th percentile were thus selected as the thresholds for ETCN events in this study. Here, an EC event refers to a decrease in the daily average temperature $(T C N<0)$ under the 10th percentile, while an EW event refers to an increase in the daily average temperature $(T C N>0)$ greater than the 90th percentile (Cai et al. 2020; Shi et al. 2018).

\subsection{Bilinear interpolation}

Due to the different resolutions of CMIP6 models, the bilinear interpolation method is used in this paper to uniformly interpolate the data of each model to the meteorological stations (Jiang et al. 2020). Then, the model simulation results are compared with the observation results to evaluate the ability of each climate model to simulate ETCNs in China.

\subsection{Linear trend analysis}

The long-term trend of an air temperature time series was analyzed using the linear tendency estimation method (Tokarska et al. 2020). A simple linear regression was performed between the temperature variable $(y)$ and the corresponding time $(x)$ :

$$
y=a x+b
$$

where $a$ is a linear regression coefficient representing the rate of change in ETCN events. A positive or negative value indicates an increasing or decreasing trend of ETCN events, respectively. The trend results were tested for significance using the t-test at the $95 \%$ confidence level.

\subsection{Evaluation indexes of the performances of CMIP6 models}

To assess the performances of the simulations against the observations, three statistical indexes were considered: the correlation coefficient $(R)$, which measures the correlations between the simulations and observations, and the root mean square error (RMSE) and BIAS, which measure the overall accuracy of the simulations. These three indexes were calculated as follows:

$$
B I A S=\frac{1}{n} \sum_{i=1}^{n}\left(O_{i}-M_{i}\right)
$$

$$
R=\frac{\sum_{i=1}^{n}\left(O_{i}-O_{m i}\right)\left(M_{i}-M_{m i}\right)}{\sqrt{\sum_{i=1}^{n}\left(O_{i}-O_{m i}\right)^{2}} \cdot \sqrt{\sum_{i=1}^{n}\left(M_{i}-M_{m i}\right)^{2}}}
$$




$$
R M S E=\sqrt{\frac{1}{n} \sum_{i=1}^{n}\left(O_{i}-M_{i}\right)^{2}}
$$

where $O_{i}$ and $M_{i}$ describe the observed and simulated ETCN event frequencies and $\mathrm{n}$ is the number of samples; a good model will have an $R$ value close to 1 and BIAS and RMSE values of almost 0 .

We selected the Taylor skill score (TS) to assess the comprehensive performances of the models. The TS is defined according to Wang et al. (2018) as follows:

$$
T S=4(1+R)^{2} /\left[\left(\frac{\sigma_{M}}{\sigma_{O}}+\frac{\sigma_{O}}{\sigma_{M}}\right)^{2}\left(1+R_{o}\right)^{2}\right]
$$

where $R$ indicates the spatial correlation coefficient between the observed and simulated frequencies of ETCN events and $R_{O}$ is the maximum attainable correlation coefficient. The parameters $\sigma_{M}$ and $\sigma_{O}$ are the standard deviations of the simulations and observations, respectively. A score closer to 1 indicates a better consistency between the observations and simulations, while a score of 0 indicates no match at all. TS focuses on the performances of the correlation coefficient and variance, according to Guo et al. (2021).

To analyze the abilities of the models with respect to temporal variations, we asked the models to reproduce the temporal standard deviation. Therefore, we used the interannual variability skill (IVS) to evaluate the models (Zhu et al. 2020; Kim et al. 2020). The formula is as follows:

$$
I V S=\left(\frac{S T D_{m}}{S T D_{O}}-\frac{S T D_{O}}{S T D_{m}}\right)^{2}
$$

where $S T D_{m}$ and $S T D_{o}$ are the interannual standard deviations of the simulated and observed data, respectively. Small IVS values indicate better performances between the CMIP6 models and the reference datasets (Fan et al. 2020).

\subsection{Multimodel ensemble mean}

To eliminate systematic errors within the model, we uses the multimodel ensemble average (MME) of 36 GCMs (Mudryk et al. 2020; Bai et al. 2021), calculated as follows:

$$
\operatorname{MME}(t)=\frac{1}{N} \sum_{i=n}^{N} P_{n}(t)
$$

where $\operatorname{MME}(t)$ is the ensemble mean at time $t, N$ is the total number of GCMs and $P_{n}(t)$ is the projection of the nth GCM at time $t$.

\subsection{Comprehensive Rating Index}

According to these multiple evaluation indexes, the rank of each model can be obtained. The 
comprehensive rating index $(C R I)$ was introduced to calculate the comprehensive rank of each model (Rivera and Arnould, 2020; Zhang et al. 2018).

$$
C R I=1-\frac{1}{1 \times n \times m} \sum_{i=1}^{n} \operatorname{rank}_{i}
$$

In the above formula, $\mathrm{m}$ is the number of models (here, we used 36 ); $\mathrm{n}$ is the number of indicators used for the evaluation; and $r a n k_{i}$ is the rank of the model according to its simulation ability based on evaluation index $i$. The closer $\operatorname{rank}_{i}$ is to 1 , the closer $C R I$ is to 1 , indicating a better simulation effect of the model.

\section{Results}

\subsection{Annual cycle}

The observation results show that from 1981 to 2013, the annual average frequency of EW events in China was higher than that of EC events; these frequencies were $18.825 \mathrm{~d}$ and $15.973 \mathrm{~d}$, respectively. In terms of different seasons, the frequencies of EW events in spring, summer and winter were higher than those of EC events, and the frequency of EW events in autumn was slightly lower than that of EC events. EW events occurred most often in spring (5.163 days) and least often in autumn (4.321 days). In contrast, EC events occurred most often in autumn (4.323 days) and least often in spring (3.683 days). Therefore, ETCN events are most likely to occur in the spring and autumn seasons.

Additionally, obvious regional differences exist in the spatial distributions of EW and EC events. Most EW events occurred in the SC, ENW and JH regions, with an average annual frequency of more than 18.8 days (Fig. 2 and Fig. 3). In spring and summer, EW events mainly occurred in Northwest China (including in the ENW and WNW regions), and in autumn and winter, EW events mainly occurred in the JH and SC regions. Notably, regardless of the region or season, the TP region had the fewest EW events and the most EC events. The annual average frequency of EC events was 16.951 days. The frequency of EC events was the lowest in the SC region, especially in summer, autumn, and winter. EC events were least frequent in the WNW region in spring, at 3.524 days. Generally, EW events mainly occurred in the SC and JH regions, while EC events mainly occurred in the TP, NEC, and NC regions.

The seasonal cycle of the occurrence frequencies of EW and EC events in China were simulated by 36 CMIP6 models. The results show that the CMIP6 models can capture annual cyclic fluctuations well. The correlation coefficient of EW events was generally higher than that of EC events; thus, CMIP6 models reproduce the annual cycle of EW events more accurately than that of EC events. Except for that of the CESM2-WACCM model, the correlation coefficients between the 
simulated and observed annual cycles exceeded 0.90 for EW events in China. However, the correlation coefficients of EC events in China were low, ranging from 0.514 (MIROC6) 0.985 (GFDL-CM4). Regarding the regions, the models simulated the seasonal cycles well in the NEC, TP, WNW and ENW regions, and the correlation coefficients generally exceeded 0.9 in these regions. In this study, when the simulation result of the MME was greater than those of 4 (approximately 90\%) of the individual CMIP6 models, the MME is considered to be able to improve the model simulation ability. The results reveal that the MME can only improve the simulation ability of the annual cycle of EC events in the WNW region, and individual CMIP6 models are better for simulating events in most areas.
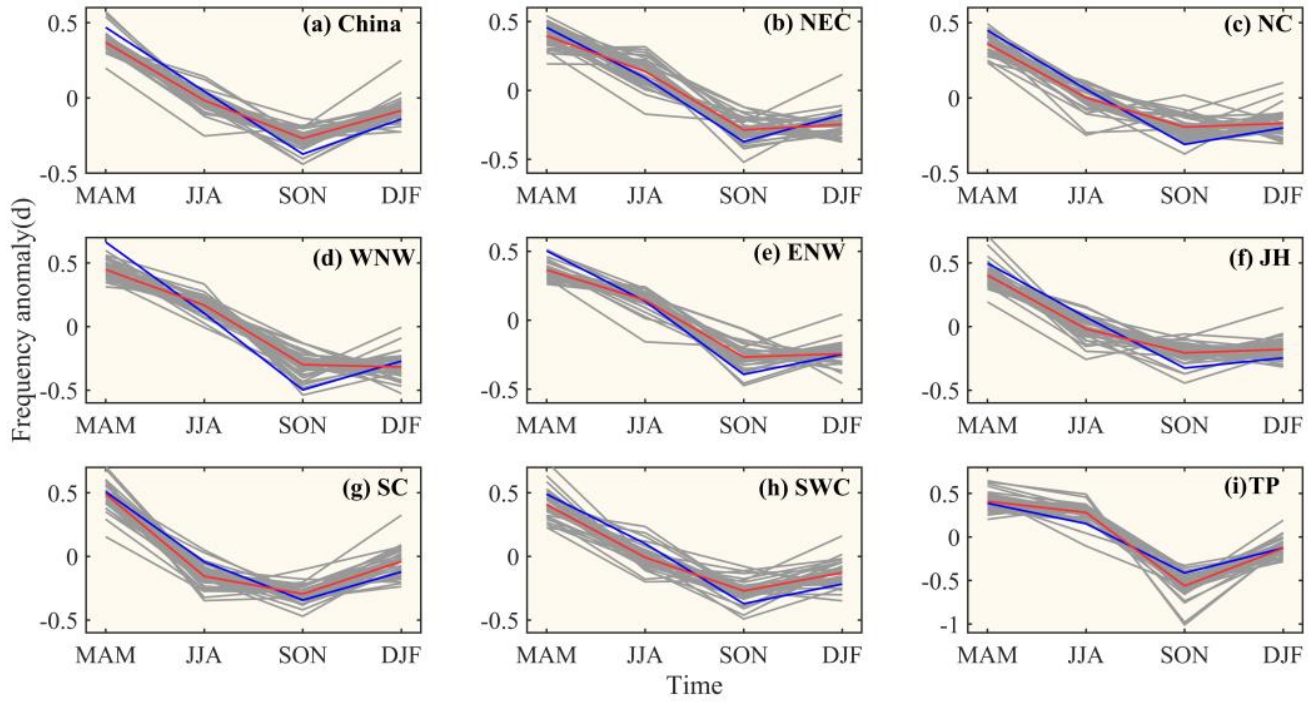

Fig. 2 Seasonal cycles output by individual CMIP6 models (gray)and the MME (blue) and observed (red) warming
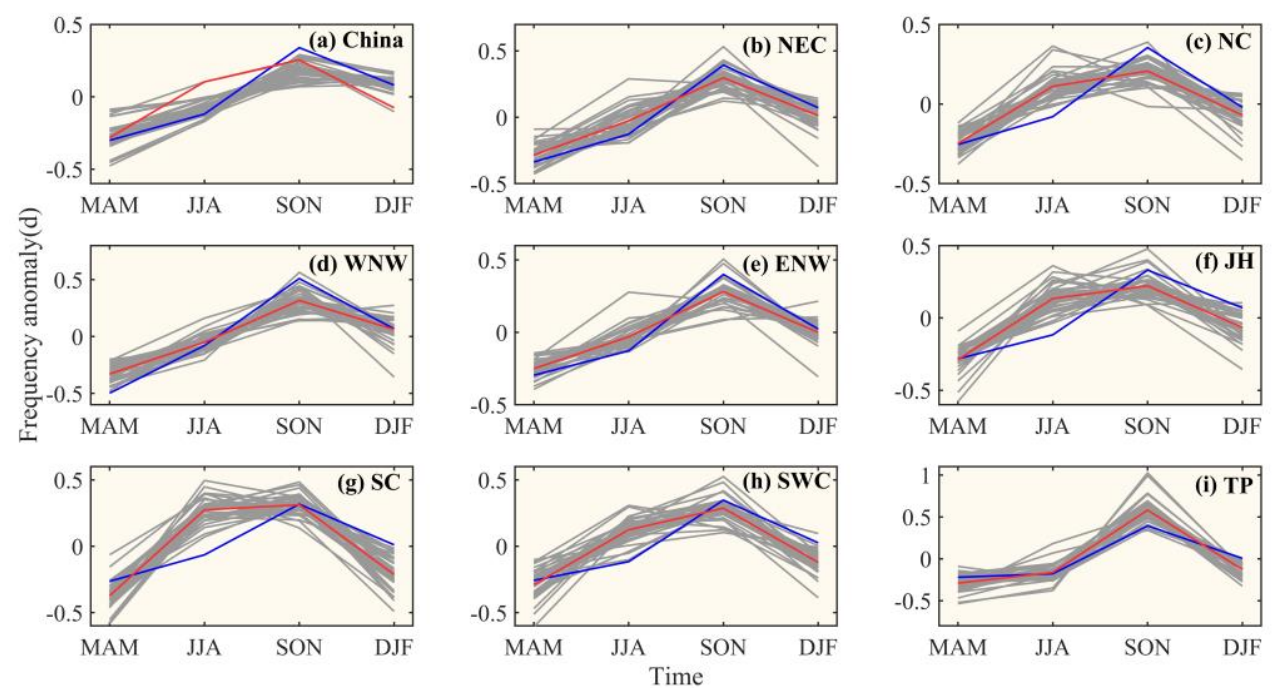

Fig. 3 Same as Fig. 2 but for cooling events 


\subsection{Climatology}

Fig. 4 and Fig. 5 shows the difference in the spatial distributions between the EW and EC events simulated by CMIP6 models and those observed in China. Generally, CMIP6 models can basically capture the spatial patterns of EW and EC events in China, but some deviation still exists. Most CMIP6 models overestimated the frequency of EW events in China; the annual average bias ranged from approximately $0.627 \mathrm{~d}$ (CanESM5) 1.694 d (ACCESS-CM2), and the RMSE values were 0.922 (CanESM5)-1.820 (ACCESS-CM2). However, the frequency of EW events simulated by some models in the TP region in autumn was underestimated, with biases of approximately $0.439 \mathrm{~d}$ (INM-CM5-0) 0.449 d (MIROC6), and the RMSEs were 0.176 (EC-Earth3) 0.514 (INMCM5-0). Generally, the NEC simulations were the closest to the observations, especially in spring. The biases between the simulations and observations were approximately -0.135 d (MPI-ESM1-2LR) 0.252 d (CESM2-FV2) in this region, and the RMSEs were 0.120 (GFDL-CM4) 0.287 (CESM2-FV2).

In addition, the annual average number of EC events in China is overestimated as a whole, which is consistent with the conclusion obtained for EW events. The biases range from approximately 0.118d (IITM-ESM) 1.039d (CanESM5), and the RMSEs are 0.515 (EC-Earth3Veg-LR) 1.141 (CanESM5). Interestingly, CanESM5 exhibited good performance in simulating EW events but poor performance in simulating EC events. In addition, except for in the TP region, the CMIP6 model simulations underestimated autumn EC events in China, especially in the NC, ENW, and WNW regions, with 29 of the 36 models displaying negative biases.

The TS results show that the EW event simulation score is generally lower than that of EC events. The TS scores of most CMIP6 models simulating EW events were above 0.4. Furthermore, models from the same institution exhibited consistent performances. For example, the simulation effects of EC-Earth-Consortium's three models (EC-Earth3, EC-Earth3-Veg, EC-Earth3-Veg-LR) were the best, especially that of EC-Earth3-Veg-LR, and their TS score was 0.601. Thus, models with high resolutions were revealed to output better simulations of EW events than models with low resolutions (Sillmann et al., 2013). From the perspective of different seasons, the TS scores for simulations of EW events in autumn were high, at 0.385 (FGOALS-f3-L) 0.559 (EC-Earth3-Veg), followed by those of EW events in spring, at 0.307 (CESM2-WACCM) 0.517 (EC-Earth3-VegLR). However, the TS scores for the simulations of EW events in summer were generally low, ranging from 0.247 (NorCPM1) to 0.456 (EC-Earth3-Veg). Regarding the different regions, the TS scores obtained for the simulations of EW events in the SC region were generally high, with an 
values in spring and summer in the SC region and in autumn and winter in the $\mathrm{NC}$ region are lower. Unlike the EW events, the TS scores of most models simulating the annual average number of EC events in China were greater than 0.5. Among them, the TS score of MRI-ESM2-0 was the highest, at 0.595. In terms of different seasons, the TS scores for the simulations of spring EC events in China ranged from 0.336 (CESM2-WACCM) 0.699 (IPSL-CM6A-LR), followed by those for the simulations of winter EC events, which ranged from 0.292 (ACCESS-ESM1-5) $\sim 0.595$ (MRIESM2-0); the summertime EC event TS scores were generally low, ranging from 0.131 (IPSLCM6A-LR) 0.506 (GFDL-ESM4), consistent with the conclusions obtained for the EW events. Regarding the different regions, the TS scores for the simulations of EW events in the SC region were generally high, with annual averages ranging from 0.386 (MPI-ESM-1-2-HAM) $\sim 0.714$ (BCC-ESM1). The TS scores obtained in the TP region were lower in spring, summer and autumn, but the TS values were higher in winter, ranging from 0.137 (BCC-ESM1) 0.502 (NorESM2-MM) as shown in Fig. 6.

The MME could not improve the simulation results of the annual average number of EW events, but the MME performed better for winter; the RMSE was 0.517 , and the TS score was 0.453 , which was better than all individual CMIP6 models. From the perspective of different regions, the MME improved the simulation results in the JH, WNW, and ENW regions. In summary, the MME could effectively improve the simulation results of wintertime EW and EC events, especially EC events. 

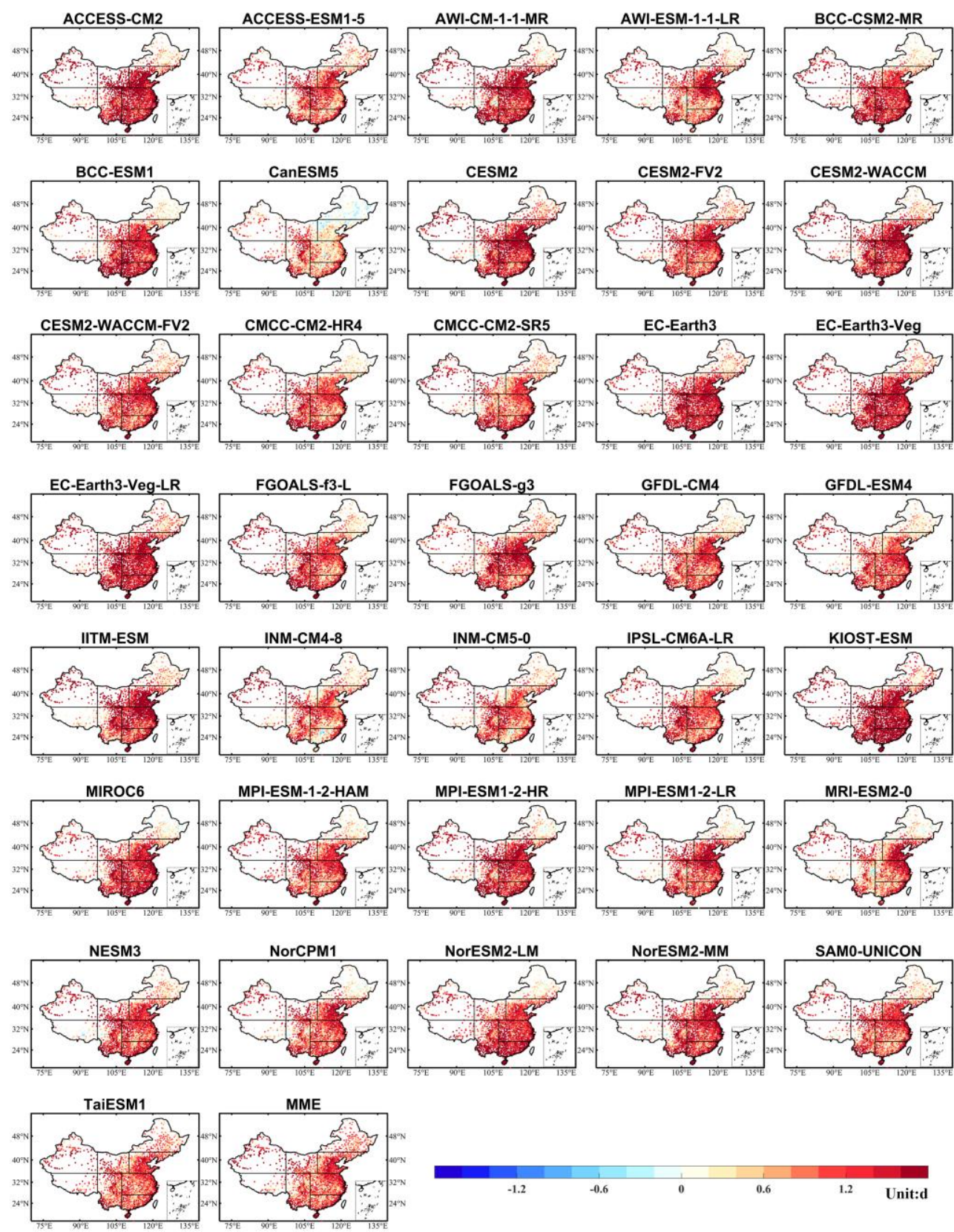

Fig. 4 Spatial distribution of the relative bias for EW events between the observations and the selected GCMs as well as between the observations and the MME from 1981-2013. The black solid lines indicate the subregions. 

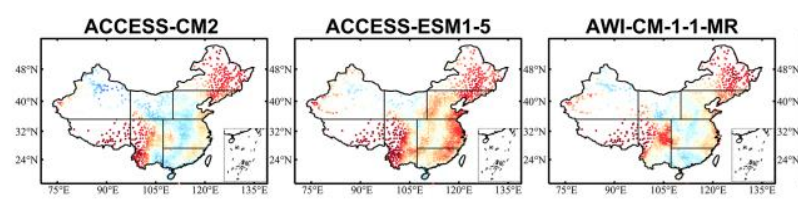

CESM2
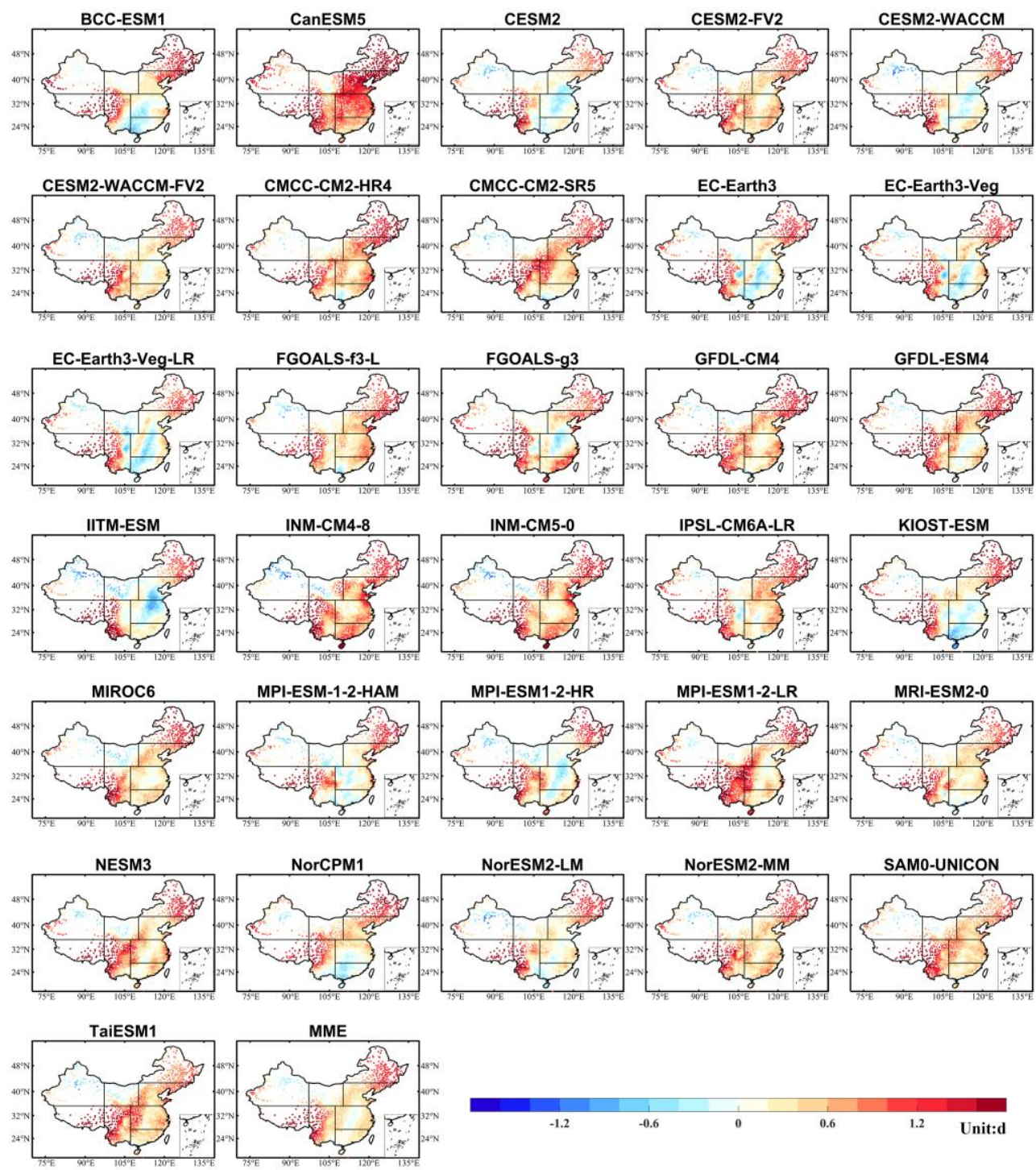

Fig. 5 Same as Fig. 4 but for EC events.

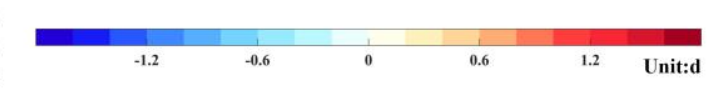



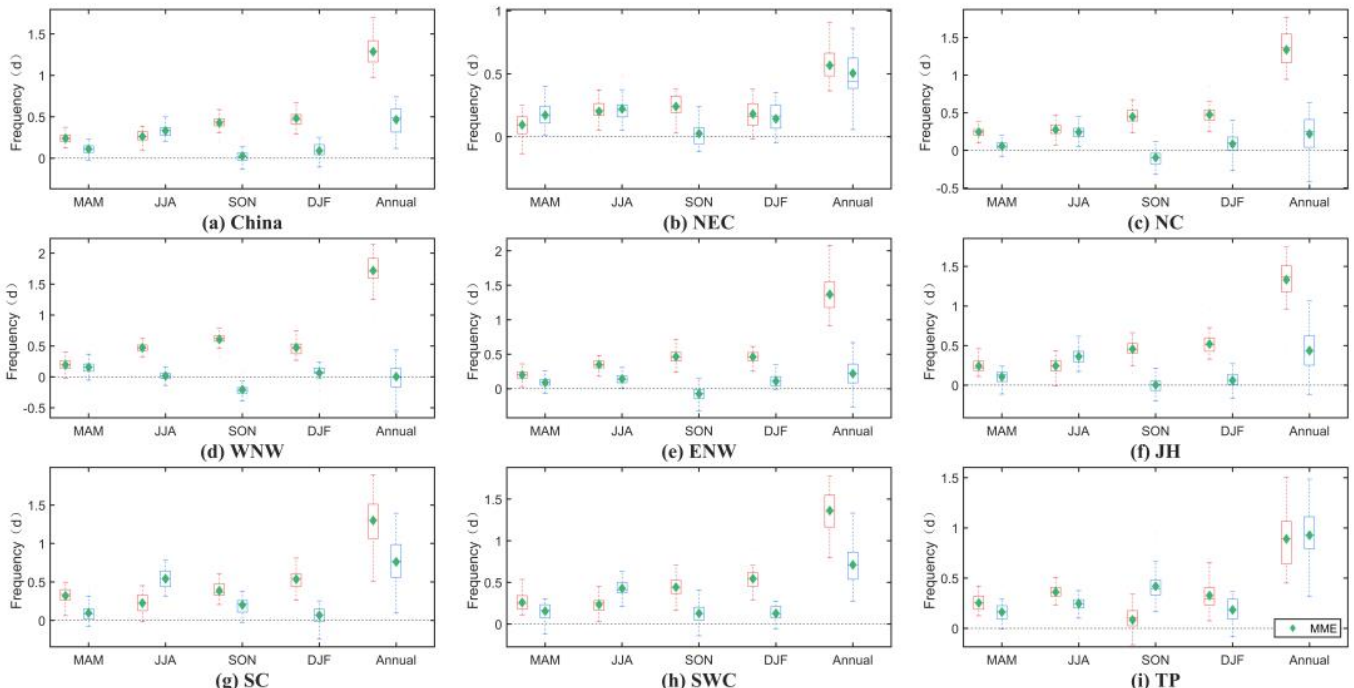

Fig. 6 Box-and-whisker plots for relative bias between the observations and the selected GCMs in the different subregions. The boxes indicate the interquartile model spread (range between the 25 th and 75 th percentiles). The red box indicates EW events and the blue box indicate EC events. the green solid marks within the boxes show the MME results.

\subsection{Trend analysis}

The observation results revealed that the annual average EW and EC event frequencies showed increasing trends with no statistical significance from 1981 to 2013 in China. In terms of the four seasons, the EW and EC events simulated in spring, summer, and winter showed no upward trends $(\mathrm{P}>0.05)$, while those simulated in autumn showed a downward trend $(\mathrm{P}>0.05)$.

Among them, the annual average increasing (decreasing) rates of EW events in spring, autumn, and winter were higher than those of EC events, but the opposite was true in summer. The increasing rate of EW events was fastest in winter $(0.169 \mathrm{~d} / 10 \mathrm{a})$ and slowest in summer $(0.022 \mathrm{~d} / 10 \mathrm{a})$. However, the increasing rate of EC events was fastest in summer $(0.099 \mathrm{~d} / 10 \mathrm{a})$ and slowest in winter $(0.032$ $\mathrm{d} / 10 \mathrm{a})$. As determined from the spatial distributions, except for in the SW and TP regions, the trends in most areas were not significant. The annual average numbers of EW events and EC events in the TP region showed significant downward trends, at $-0.854 \mathrm{~d} / 10 \mathrm{a}(\mathrm{P}<0.05)$ and $-0.772 \mathrm{~d} / 10 \mathrm{a}(\mathrm{P}<$ 0.05 ), respectively, and these numbers decreased by 2.818 days and 2.548 days throughout the study period, respectively. However, the average annual increasing trend of EW events in Southwest China was $0.576 \mathrm{~d} / 10 \mathrm{a}(\mathrm{P}<0.05)$, and these events increased in number by 1.901 days throughout the study period as shown in Fig. 7 and Fig. 8.

Whether a model can simulate the trend changes in EW and EC events is an important index used to examine the simulation ability of the model. As shown in Fig. 9 and Fig. 10, large differences 
could not reflect the trend changes in EW or EC events in China, and only a few models had optimal simulation results. For the simulation of EW events, only four models could simulate the increasing trend of the annual average number of EW events in China. The NorESM2-MM model was the closest to the observations, with a change rate of $0.398 \mathrm{~d} / 10 \mathrm{a}$, which was only higher than the observed rate of $0.05 \mathrm{~d} / 10 \mathrm{a}$. Most models could simulate the observed decreasing trend in autumn but could not reflect the increasing trends in spring, summer, or winter. Generally, the spring NorESM2-MM, summer INM-CM5-0, autumn CESM2, and winter INM-CM4-8 simulated trends of EW events in China were good agreement with the observations. From the perspective of different regions, the models could simulate the decreasing trend of EW events in the TP region and could also capture the decreasing trend of summer EW events in the NE, NC, ENW and JH regions. However, only individual models could simulate the increasing trend of EW events in spring.

Regarding the simulation of EC events, only five models could simulate the increasing trend of the annual average number of EC events in China. The outputs of the NorESM2-MM model were closest to the observations, with a change rate of $0.149 \mathrm{~d} / 10 \mathrm{a}$, which was $0.01 \mathrm{~d} / 10 \mathrm{a}$ lower than the observed value. Most of the models could only simulate the decreasing trend in autumn. Among them, the autumn BCC-ESM- and winter AWI-CM-1-1-MR-simulated trends of EW events in China were in good agreement with the observations, and the optimal models in spring and summer were consistent with the EW events. Regarding the studied regions, most models could simulate the trends of EC events in the NC and TP regions well except for in summer, and most of the models could simulate the decreasing trends in the $\mathrm{NE}, \mathrm{NC}, \mathrm{SC}$, and $\mathrm{TP}$ regions and the increasing trend in the ENW region in spring.

The MME average simulation results showed decreasing trends in EW and EC events in China in all four seasons, and the simulation results of EW and EC events were quite different among different regions (Fig. 11). The MME could effectively improve the simulation ability of autumn EW events in China, especially in the JH region. The trend obtained by the MME for autumn EW events was $-0.069 \mathrm{~d} / 10 \mathrm{a}$, which was only $0.018 \mathrm{~d} / 10 \mathrm{a}$ lower than the observed trend and was better than the outputs of any single model. In terms of EC events, the MME results were not significantly improved. Regionally, the EC events in the SC and TP regions in spring, in the SC region in autumn, and in the NEC region in winter were significantly improved, especially in the TP region in spring. The trend of EC events simulated by MME was $-0.208 \mathrm{~d} / 10 \mathrm{a}$, which was only $0.005 \mathrm{~d} / 10 \mathrm{a}$ lower than the observed trend and was better than any single model. However, for the other regions, the effect of the MME simulation was not as good as that of the simulations of most individual models. Although some models could simulate the trends of the EW and EC event frequencies, the simulations of the change rates were much weaker and differed significantly from the observed 

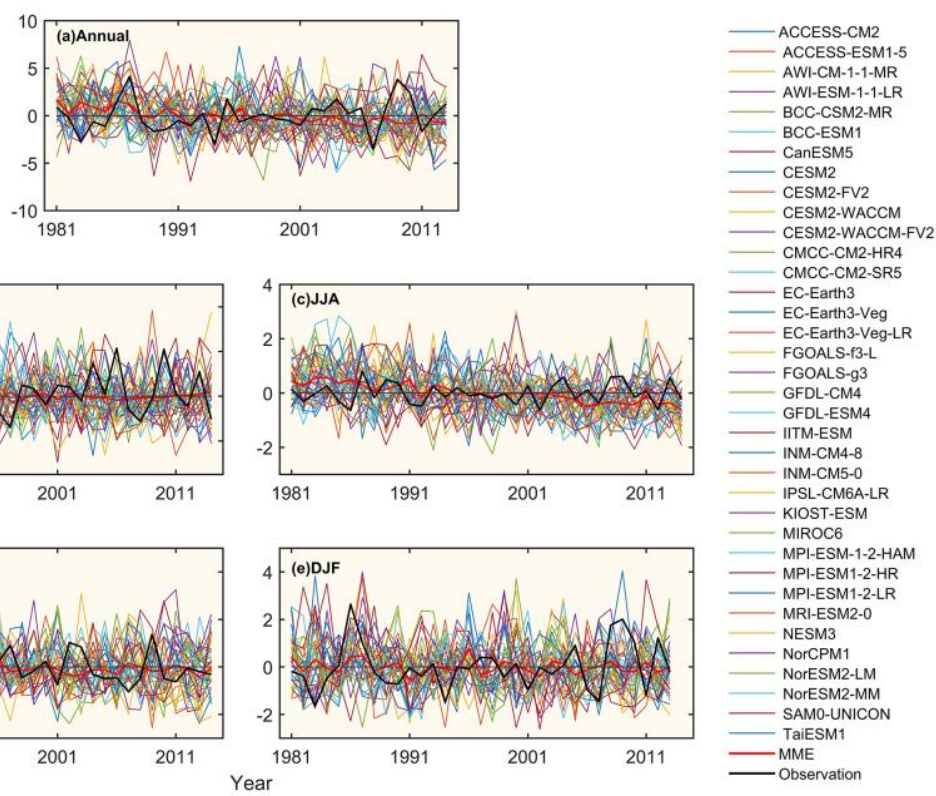

Fig. 7 CMIP6 models simulating the frequency time series of EW events in China
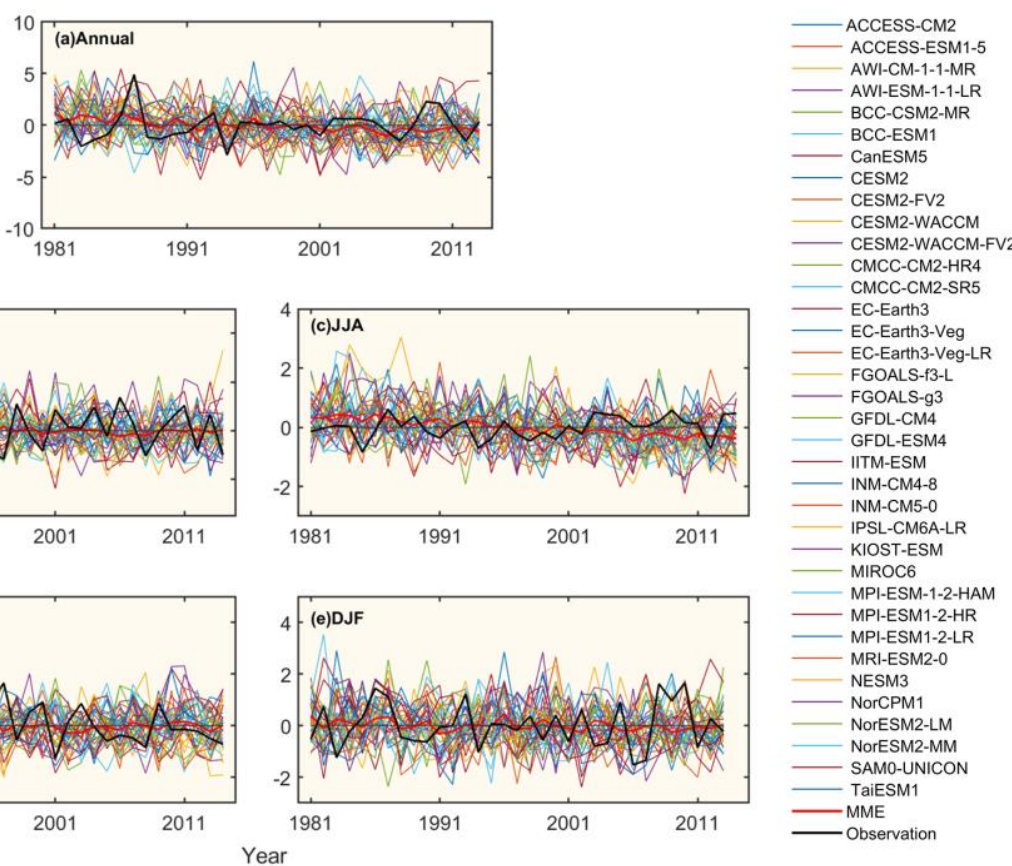

Fig. 8 Same as Fig. 7 but for EC events 

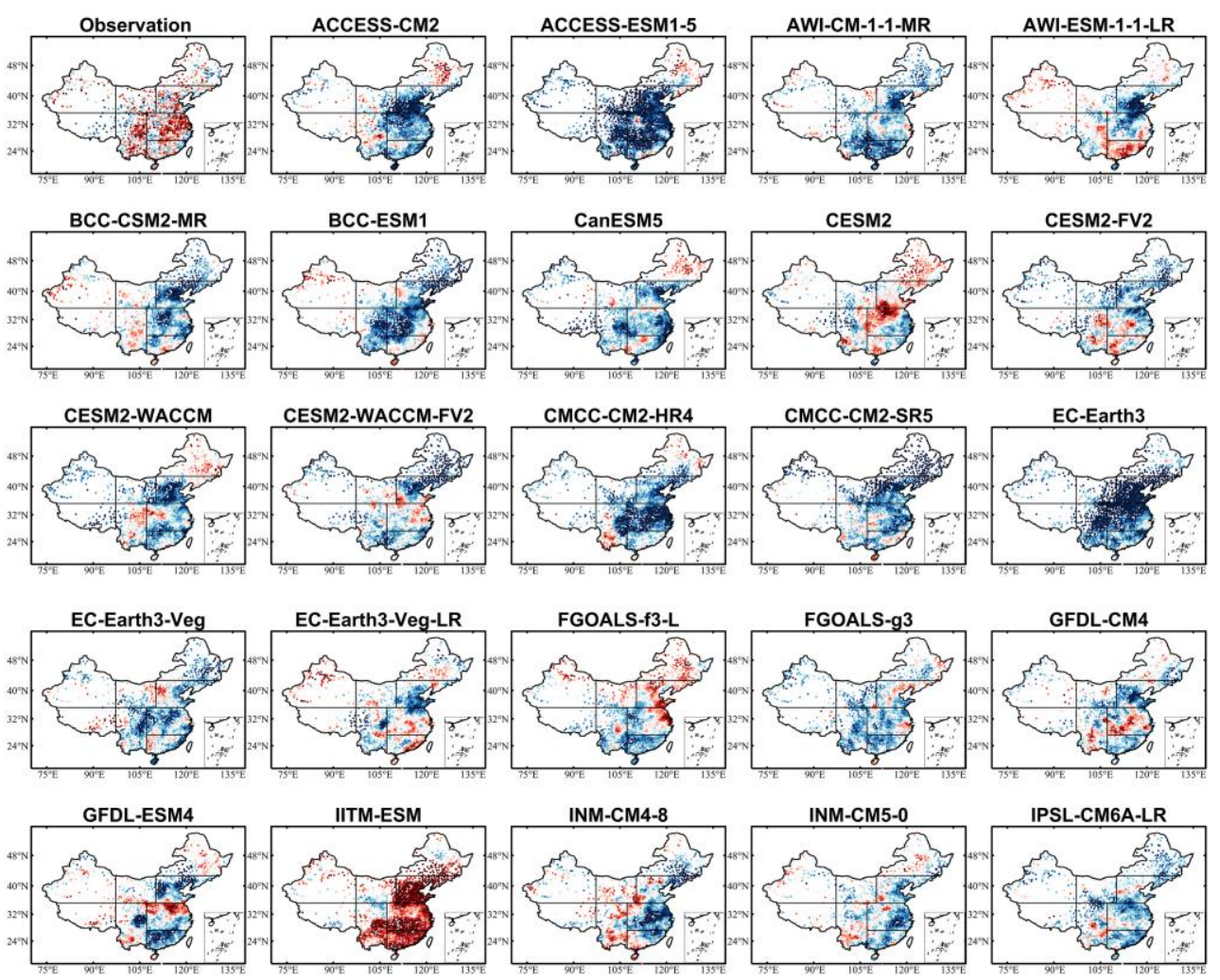

IPSL-CM6A-LR
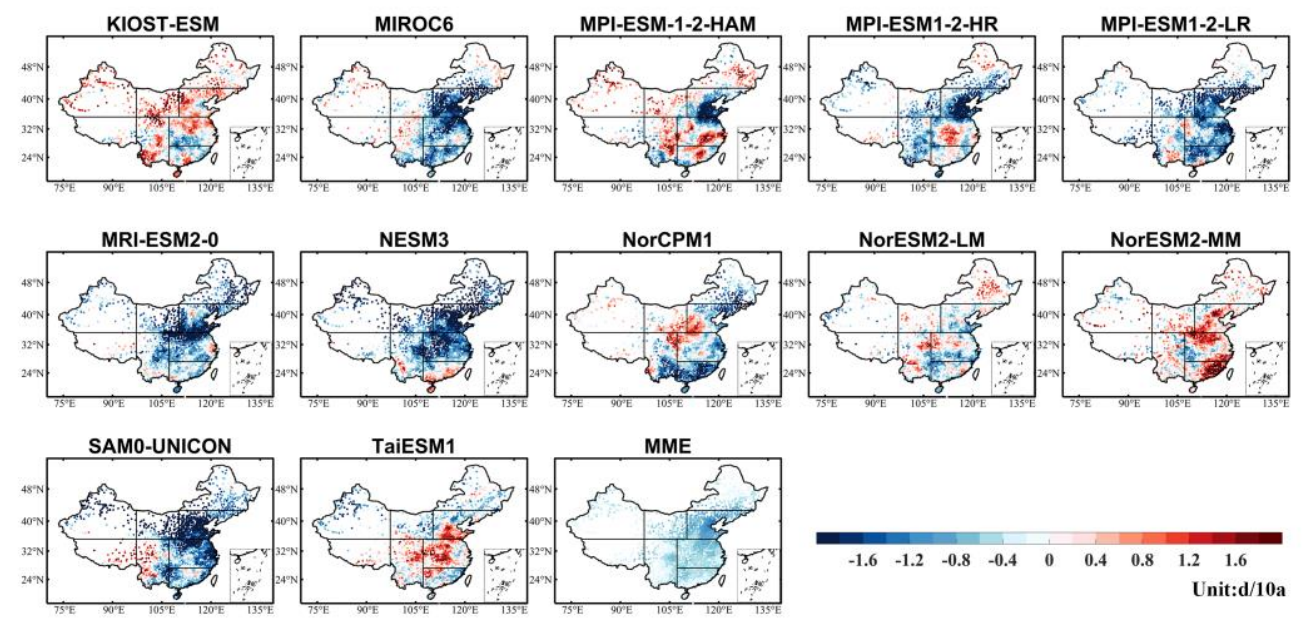

Fig. 9 Spatial distribution of annual EW events trends during 1981-2013 from the observations, MME, and the selected GCMs. The black solid lines indicate the subregions. 

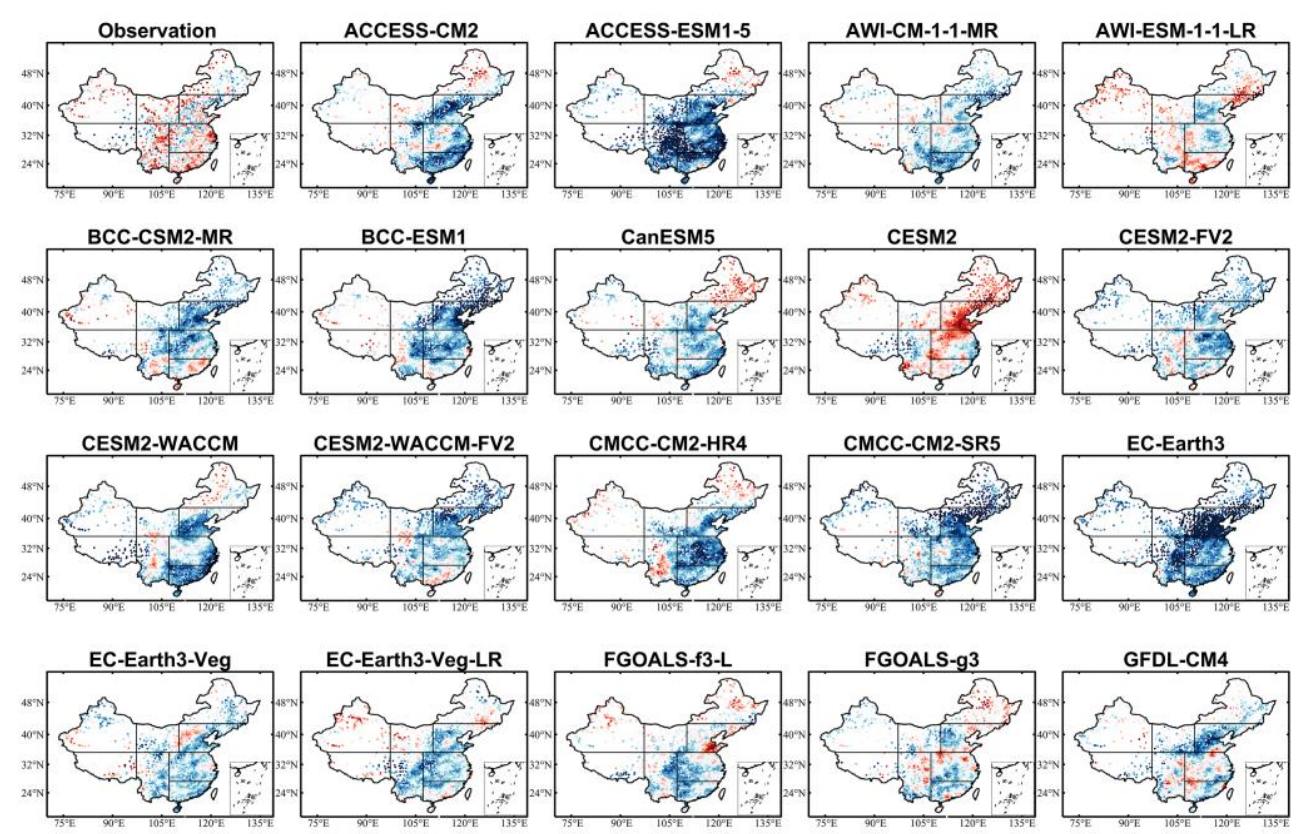

GFDL-CM4
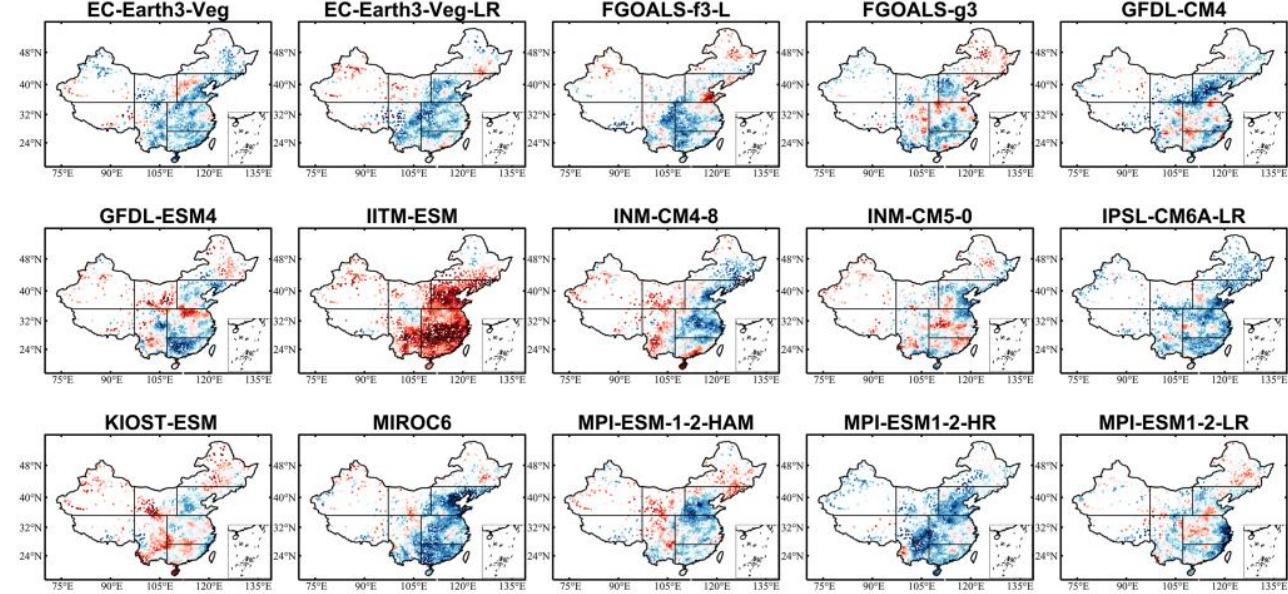

IPSL-CM6A-LR
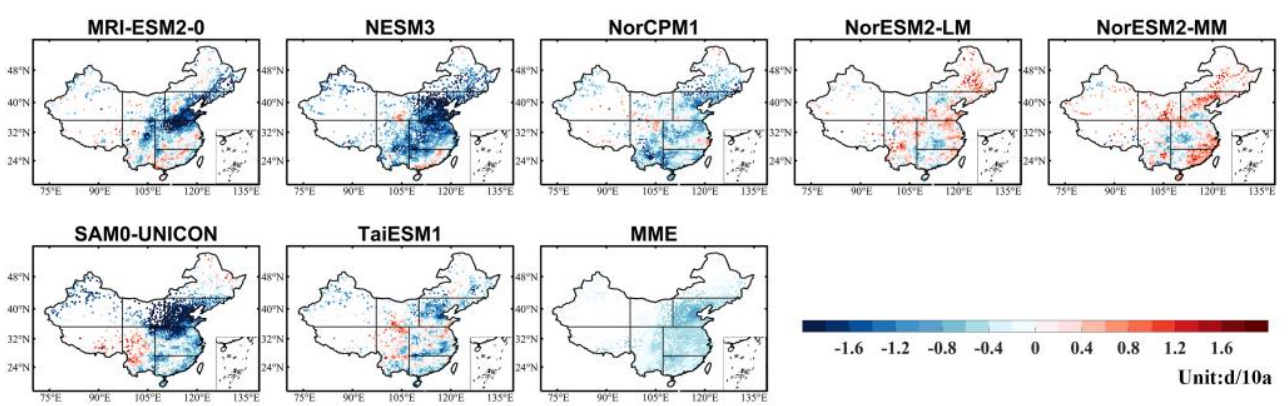

Fig. 10 Same as Fig. 9 but for EC events 

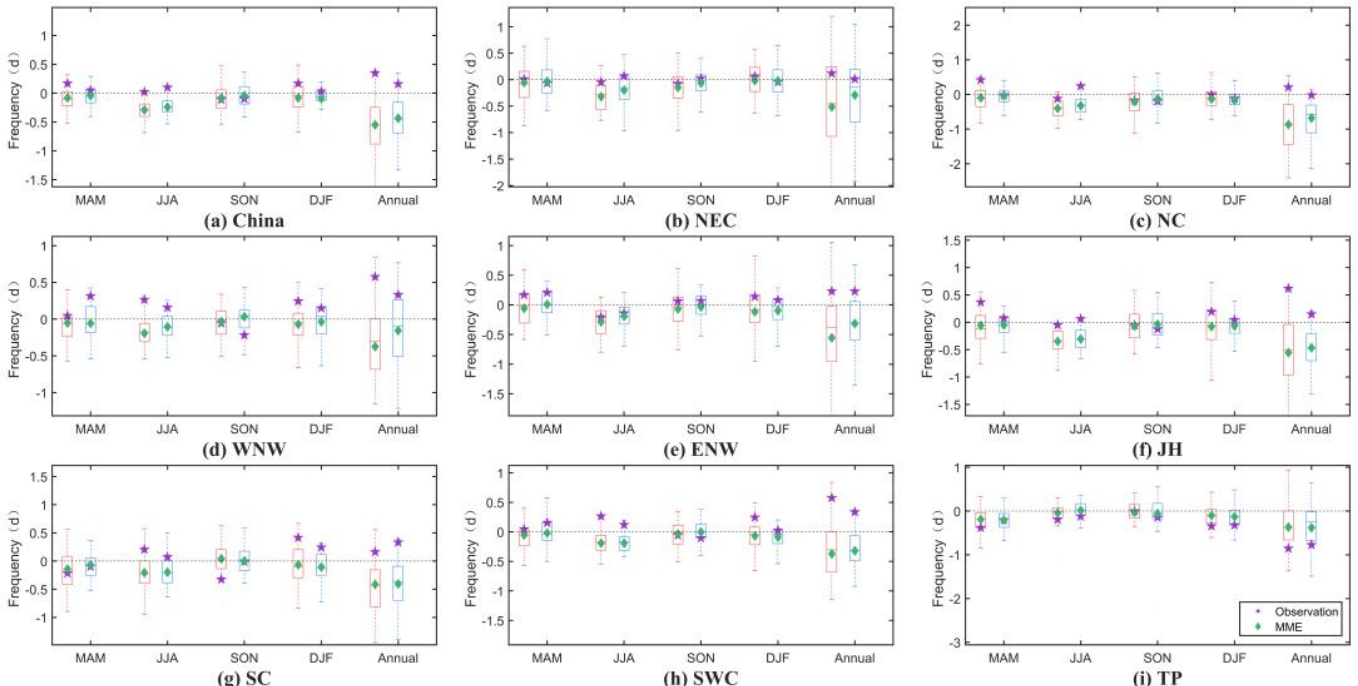

Fig. 11 Box-and-whisker plots for the trends of the selected GCMs in the different subregions. The boxes indicate the interquartile model spread (range between the 25 th and 75 th percentiles). The red box indicates EW events and the blue box indicate EC events. the green solid marks within the boxes show the MME results and the purple solid marks indicate the observation.

\subsection{Interannual variability}

The assessment of temporal variability is another index used to measure the simulation ability of a model. In this paper, IVS was used to evaluate the consistency of temporal variabilities between the modelled and observed data. The results are shown in Fig. 12. Overall, the temporal variability simulations of EC events were generally better than those of EW events. Specifically, for EW events, the annual average IVS in China ranged from 0 (BCC-CSM2-MR) to 1.561 (IITM-ESM). Regarding the different seasons, the IVS was highest in summer, with IVS values greater than 1 obtained for approximately 32 models. However, the IVS values were lower in spring and winter, ranging from 0 (IPSL-CM6A-LR) $\sim 0.735($ CESM2-WACCM) and from 0 (TaiESM1) 0.676 (CESM2), respectively. In the different regions, the IVS values obtained in the NEC, NC, WNW, and ENW regions in spring were generally lower than those obtained in the SC region, while the IVS values obtained din the SC, SW, and JH regions in autumn were generally lower than those obtained in the $\mathrm{NC}$ region. The annual average IVS values of the TP region were higher than those of other regions, at 0.484 (GFDL-CM4) 11.095 (CESM2-WACCM), likely because the models could hardly reproduce the EW events related to the complex topography (You et al. 2020).

For EC events, the annual average IVS in China ranged from 0.003 (TaiESM1) to 1.312 (IITMESM), the IVS in summer was generally higher, ranging from 0.008 (FGOALS-g3) to 9.833 
lower in spring, autumn and winter, ranging from 0.001 (CESM2-FV2) 0.670 (CESM2-WACCM), from 0 (MPI-ESM1-2-LR) 0.398 (TaiESM1) and from 0.001 (BCC-CSM2-MR) 0.371 (MPIESM1-2-LR), respectively. In each region, IVS was generally lower in spring except in the NEC region, while in the TP and SW regions, IVS was higher than in other regions.

The MME has difficulty reproducing the interannual variabilities in the annual average EW and EC events in China, which was consistent with the findings described in Jiang et al. (2015), who pointed out that most models have difficulty reproducing the interannual variability of extreme precipitation in China. However, the MME presented a better simulation of the interannual variability in summer, and the IVS of the EW event was 0.141 in China, second only to the FGOALS-g3 simulation results. Notably, the summer IVS in the NC region was significantly improved to 0.702 , while the improvements in other regions were not obvious. The IVS of summer EC events in China obtained for the MME was 0.466 , which was second only to the FGOALS-g3 simulation results and was consistent with EW events; however, the regional improvement was, likewise, not obvious.
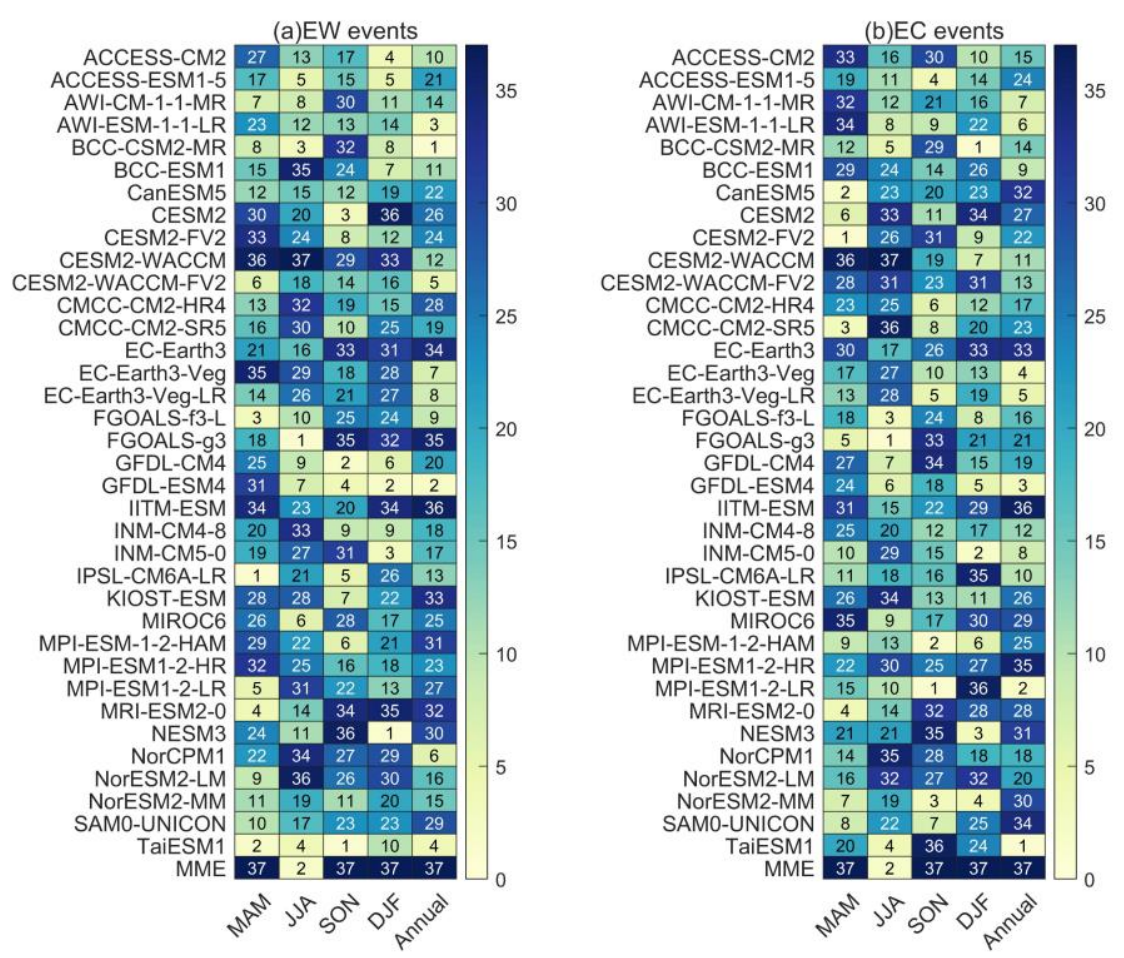

Fig. 12 Ranking of CMIP6 models for EW and EC events based on the IVS over China

\subsection{Overall model ranking}

In this study, different evaluation indexes were used to select the optimal individual CMIP6 models and the MME averages in simulating the annual cycles, climatology, interannual variabilities, 
and trends of EW and EC events in China. Because of the discrepancy inherent in model ranking, a comprehensive evaluation index (CRI) was adopted to select the most skillful models in different regions and seasons based on the models' overall rankings. As shown in Table 2 and Table 3, the optimal models for simulating EW and EC events differed among different seasons and regions. For the annual average EW events in China, GFDL-ESM4 had the best simulation performance. FGOALS-f3-L in spring, FGOALS-g3 in summer, and GFDL-CM4 in autumn and winter were the preferred models for simulating EW events. For the annual average EC events in China, the ECEarth3-Veg-LR model had the best simulation performance, and the spring EC-Earth3-Veg-LR, summer GFDL-CM4, autumn EC-Earth3-Veg, and winter EC-Earth3-Veg-LR were the preferred models for EC events. Notably, the best models for simulating EC events all had relatively high resolutions, whereas this expectation was not extendable to the EW events.

It is worth noting that the MME average significantly improved the climatology simulations of EW and EC events in winter in China. This was mainly because the MME average reduced the bias and uncertainty among climate models and output information that was closer to the observed results (Wang et al. 2018; Almazroui et al. 2017). However, the MME average did not significantly improve the overall simulation of EW events in China and showed significant improvements for simulating EC events in winter in the entirety of China and in the WNW region; however, the MME was not the best scheme. A possible reason for this result is that the CRI score includes the IVS index value. Previous studies have shown that the MME average has a large bias when simulating interdecadal variability, which may be due to the models of the MME canceling each other out and smoothing the natural variability within the climate system. Thus, the long-term trends of EW and EC events were underestimated, which was consistent with the conclusions of temperature studies conducted by Zhao et al. (2014) and Li Xiaofei (2019). Therefore, the MME averaging method should be used cautiously when simulating the trends and interannual variability rates of EW and EC events.

Table 2 Ranking of CMIP6 models for EW events by different evaluation indicators based on the CRI

\begin{tabular}{cccccc}
\hline & MAM & JJA & SON & DJF & Annual \\
\hline NEC & CanESM5 & FGOALS-g3 & IPSL-CM6A-LR & CanESM5 & GFDL-ESM4 \\
NC & FGOALS-f3-L* & ACCESS-ESM1-5 & IPSL-CM6A-LR & GFDL-ESM4 & KIOST-ESM \\
ENW & CanESM5 & TaiESM1* & TaiESM1* & BCC-ESM1 & NorCPM1 \\
WNW & GFDL-ESM4 & FGOALS-g3 & EC-Earth* & GFDL-CM4 & GFDL-ESM4 \\
SC & FGOALS-g3 & MRI-ESM2-0 & SAM0-UNICON & GFDL-CM4 & MPI-ESM1-2-HR* \\
SWC & MIROC6 & MIROC6 & CESM2-WACCM-FV2 & ACCESS-CM2 & INM-CM5-0* \\
TP & ACCESS-CM2 & FGOALS-g3 & NorESM2-LM & AWI-ESM-1-1-LR* & ACCESS-ESM1-5
\end{tabular}




\begin{tabular}{cccccc} 
JH & MPI-ESM-1-2-HAM & ACCESS-ESM1-5 & TaiESM1* & CMCC-CM2-SR5 & TaiESM1* \\
China & FGOALS-f3-L* & FGOALS-g3 & TaiESM1* & GFDL-CM4 & GFDL-ESM4 \\
\hline “*” indicates a high-resolution model (resolution over $0.5^{\circ}$ ) & &
\end{tabular}

Table 3 Same as Table 2 but for EC events

\begin{tabular}{cccccc}
\hline & MAM & JJA & SON & DJF & Annual \\
\hline NEC & TaiESM1* & GFDL-CM4 & BCC-CSM2-MR* & IITM-ESM & TaiESM1* \\
NC & FGOALS-g3 & GFDL-CM4 & IPSL-CM6A-LR & EC-Earth3-Veg-LR* & EC-Earth3-Veg-LR* \\
ENW & IITM-ESM & MPI-ESM-1-2-HAM & IPSL-CM6A-LR & NorESM2-MM & AWI-CM-1-1-MR* \\
WNW & FGOALS-f3-L* & GFDL-ESM4 & EC-Earth3* & FGOALS-f3-L & GFDL-ESM4 \\
SC & EC-Earth3-Veg-LR* & BCC-CSM2-MR* & EC-Earth3-Veg* & MRI-ESM2-0* & BCC-CSM2-MR* \\
SWC & EC-Earth3-Veg-LR* & GFDL-ESM4 & FGOALS-f3-L* & NorCPM1 & BCC-CSM2-MR* \\
TP & INM-CM4-8 & EC-Earth3* & AWI-CM-1-1-MR* & FGOALS-f3-L* & IPSL-CM6A-LR \\
JH & EC-Earth3-Veg-LR* & GFDL-ESM4 & CMCC-CM2-SR5 & MRI-ESM2-0* & EC-Earth3-Veg-LR* \\
China & EC-Earth3-Veg-LR* & GFDL-CM4 & EC-Earth3-Veg* & EC-Earth3-Veg-LR* & EC-Earth3-Veg-LR* \\
\hline
\end{tabular}

\section{Discussion and Conclusion}

In this paper, we quantitatively assessed the performances of 36 CMIP6 GCMs in simulating the annual cycle, climatology, and trend of and the interannual variability in ETCN events in China and in different regions within China using multiple assessment methods and CRI metrics combined with daily average temperature data in China. These results provide a reference for model improvements and projections in the future. The following conclusions were obtained.

The observation results showed that from 1981 to 2013, the annual average frequency of EW events in China was higher than that of EC events. EW events mostly occurred in spring, while EC events mostly occurred in autumn. From the trend, the annual average numbers of EW events and EC events in China did not show any significant increasing trend. Among these trends, the increasing rate of EW events was fastest in winter and slowest in summer, while EC events showed the opposite trends.

The 36 CMIP6 models could reproduce the annual cycles of EW and EC events well. The simulation of the annual cycle of EW events was higher than that of EC events. The CMIP6 models could capture the spatial patterns of EW and EC events in China. However, most CMIP6 models overestimated the frequency of EW and EC events in China but underestimated the frequency of EC events in autumn. The TS scores were generally lower for EW events than for EC events, and the simulation effect was the best in the SC region. 
events in China but could only simulate the decreasing trend in autumn, especially in the TP region. Combining the evaluation indicators of the annual cycle, climatology, and trend of and the interannual variability in EW events and EC events, it can be concluded that the optimal models for simulating EW and EC events differ among different seasons and regions in China. GFDL-ESM4 best simulates EW events, while EC-Earth3-Veg-LR best simulates EC events in China.

In addition, although the CMIP6 climate models could reproduce the spatial pattern of the frequency of ETCN events in China, some biases still exist in the simulation of ETCN events. Previous studies have shown that uncertainties in climate models mainly result from the subgrid parameterization process (Bony and Dufresne 2005; Luan et al. 2016). Furthermore, dynamic downscaling is a useful way to reduce model uncertainty based on the best model in simulating ETCN events, as was selected here; this method can improve simulations of regional climate changes (Seo et al. 2013). To eliminate model uncertainty, we could improve the resolution of the climate model to reduce its dependence on the physical parameterization process (Randall et al. 2003; Eyring et al. 2019; Paik et al. 2020). The high-resolution model effectively improved the model performance in simulating annual EC events, but this improvement does not apply to the TP or WNW regions. This indicates that physical processes play an important role in areas with complex topography, which is still a challenging topic for the improvement of global climate models (Jiang et al. 2015). In addition, the uncertainty of observed data is another main cause of biases, such as the data uncertainty in the TP region related to the sparse station density (Yin et al. 2019). In the future, multisource observation data will be used for comparative analyses to improve the accuracy of model evaluations ( $\mathrm{Li}$ et al. 2010). The MME method used in this paper was an equalweight ensemble, whereas each model could be given different weights according to the ranking of the models' performance to obtain more accurate simulation results (Knutti et al., 2010); this will be the content of our next work.

\section{Acknowledgments}

We would like to think the China Meteorological Administration for temperature data and information. We also acknowledge the Coupled Model Intercomparison Project (CMIP) launched by the World Climate Research Program (WCRP) for CMIP6 data.

\section{Funding Statement}

This work was supported by the National Key Research and Development Program of China [grant number 2019YFA0606904]. 
All authors have read and agreed to the published version of the manuscript. Shuaifeng Song analyzed data and wrote original draft. Xiaodong Yan conceived and designed the study.

\section{Availability of data and material}

All data sets used in this study are publicly available.

\section{Code availability}

MATLAB code developed for this study is available from the authors upon request.

\section{Ethics approval}

The manuscript is conducted within the ethical manner advised by the Theoretical and Applied Climatology. Permissions or licenses were obtained.

\section{Consent to participate}

Not applicable.

\section{Consent for publication}

Authors agree to publish this paper.

\section{Conflicts of interest}

The authors declare no conflict of interest.

\section{Author information}

\section{Affiliations}

State Key Laboratory of Earth Surface Processes and Resource Ecology, Faculty of Geographical Science, Beijing Normal University, Beijing 100875, China

Shuaifeng Song, Xiaodong Yan

\section{Corresponding author}

Correspondence to Xiaodong Yan. E-mail: yxd@bnu.edu.cn. Tel:(+86)13511027765

\section{References}

Aguilar E, Aziz Barry A, Brunet M, Ekang L, Fernandes A, Massoukina M, Mbah J, Mhanda A, doNascimento DJ, 
in western central Africa, Guinea Conakry, and Zimbabwe, 1955-2006. J Geophys Res-Atmos 114(D2):356360. https://doi.org/doi:10.1029/2008JD011010

Akinsanola AA, Kooperman GJ, Pendergrass AG, Hannah WM, Reed KA (2020). Seasonal representation of extreme precipitation indices over the United States in CMIP6 present-day simulations. Environ Res Lett 15(9):094003. https://doi.org/10.1088/1748-9326/ab92c1

Akinsanola AA, Ongoma V, Kooperman GJ (2021). Evaluation of CMIP6 models in simulating the statistics of extreme precipitation over Eastern Africa. Atmos Res 254:105509. https://doi:10.1016/j.atmosres.2021.105509

Almazroui M, Islam MN, Saeed S, Alkhalaf AK, Dambul R. (2017). Assessment of uncertainties in projected temperature and precipitation over the Arabian Peninsula using three categories of Cmip5 multimodel ensembles. Earth Systems and Environment, 1(2), 1-20. https://doi:10.1007/s41748-017-0027-5

Bai H, Xiao D, Wang B, Liu DL, Feng P, Tang J (2021). Multi-model ensemble of CMIP6 projections for future extreme climate stress on wheat in the North China plain. Int J Climatol 41:E171-E186. https://doi:10.1002/joc.6674

Bony S, Dufresne JL (2005). Marine boundary layer clouds at the heart of tropical cloud feedback uncertainties in climate models. Geophys Res Lett 32(20). https://doi:10.1029/2005GL023851

Cai Q, Guan Z Y, Xu M (2020). Temporal and spatial characteristics of extreme cooling events in eastern China in winter monsoon period during 1960 and 2012. Trans Atmos Sci 43(3): 458-468. https://doi:10.13878 /j.cnki.dqkxxb.20190719001

Chen S, Liu J, Ding Y, Zhang Y, Cheng X, Hu Y (2021). Assessment of Snow Depth over Arctic Sea Ice in CMIP6 Models Using Satellite Data. Adv Atmos Sci 38(2):168-186. https://doi.org/10.1007/s00376-020-0213-5

Cheng J, Zhu R, Xu Z, Xu X, Wang X, Li K, Su H (2014). Temperature variation between neighboring days and mortality: a distributed lag non-linear analysis. Int J Public Health 59(6):923-931. https://doi:10.1007/s00038014-0611-5

Cheng J, Zhu R, Xu Z, Wu J, Wang X, Li K, Wen L, Yang H, Su H (2016). Impact of temperature variation between adjacent days on childhood hand, foot and mouth disease during April and July in urban and rural Hefei, China. Int J Biometeorol 60(6):883-890. https://doi:10.1007/s00484-015-1082-y

Easterling DR, Meehl GA, Parmesan C, Changnon SA, Karl TR, Mearns LO (2000). Climate extremes: observations, modeling, and impacts. Science 289(5487):2068-2074. https://doi:10.1126/science.289.5487.2068

Eyring V, Bony S, Meehl GA, Senior CA, Stevens B, Stouffer RJ, Taylor KE (2016). Overview of the Coupled Model Intercomparison Project Phase 6 (CMIP6) experimental design and organization. Geosci Model Dev 9(5):1937-1958. https://doi:10.5194/gmd-9-1937-2016

Eyring V, Cox PM, Flato GM, Gleckler PJ, Abramowitz G, Caldwell P, Collins WD, Gier BK, Hall AD, Hoffman FM, Hurtt GC, Jahn A, Jones CD, Klein SA, Krasting JP, Kwiatkowski L, Lorenz R, Maloney E, Meehl GA, Pendergrass AG, Pincus R, Ruane AC, Russell JL, Sanderson BM, Santer BD, Sherwood SC, Simpson IR, 
Stouffer RJ, Williamson MS (2019). Taking climate model evaluation to the next level. Nat Clim Change 9:102-110. https:// doi.org/10.1038/s41558-018-0355-y

Fan X, Miao C, Duan Q, Shen C, Wu Y (2020). The performance of CMIP6 versus CMIP5 in simulating temperature extremes over the global land surface. J Geophys Res-Atmos 125(18):e2020JD033031. https://doi:10.1029/2020JD033031

Gao Z, Zhu J, Guo Y, Luo N, Fu Y, Wang T (2021). Impact of Land Surface Processes on a Record-Breaking Rainfall Event on May 06-07, 2017, in Guangzhou, China. J Geophys Res-Atmos 126(5): e2020JD032997. https://doi:https://doi.org/10.1029/2020jd032997

Ge F, Zhu S, Luo H, Zhi X, Wang H (2021). Future changes in precipitation extremes over Southeast Asia: insights from CMIP6 multi-model ensemble. Environ Res Lett 16(2):024013. https://doi:10.1088/1748-9326/abd7ad Grise KM, Davis SM (2020). Hadley cell expansion in CMIP6 models. Atmos Chem Phys 20(9):5249-5268. https://doi.org/10.5194/acp-20-5249-2020

Grose MR, Narsey S, Delage FP, Dowdy AJ, Bador M, Boschat G, Boschat G, Chung C, Kajtar JB, Rauniyar S, Freund MB, Lyu K, Rashid H, Zhang X, Wales S, Trenham C, Holbrook NJ, Cowan T, Alexander L, Arblaster JM, Power S (2020). Insights from CMIP6 for Australia's future climate. Earths Future 8(5): e2019EF001469. https://doi:10.1029/2019EF001469

Goldberg MS, Gasparrini A, Armstrong B, Valois MF (2011). The short-term influence of temperature on daily mortality in the temperate climate of Montreal, Canada. Environ Res 111(6):853-860. https://doi:10.1016/j.envres.2011.05.022

Gough WA (2008). Theoretical considerations of day-to-day temperature variability applied to Toronto and Calgary, Canada data. Theor Appl Climatol 94(1):97-105. https://doi:10.1007/s00704-007-0346-9

Guo H, Bao A, Chen T, Zheng G, Wang Y, Jiang L, De Maeyer P (2021). Assessment of CMIP6 in simulating precipitation over arid Central Asia. Atmos Res 252:105451. https://doi.org/10.1016/j.atmosres.2021.105451

Guo Y, Barnett AG, Yu W, Pan X, Ye X, Huang C, Tong S (2011). A large change in temperature between neighbouring days increases the risk of mortality. PloS one 6(2):e16511. https://doi:10.1371/journal.pone.0016511

Ha KJ, Yun KS (2012). Climate change effects on tropical night days in Seoul, Korea. Theor Appl Climatol 109(1-2):191-203. https://doi:10.1007/s00704-011-0573-y

IPCC AR5 WGI. Climate Change: The Physical Science Basis. Contribution of Working Group I to the Fifth Assessment Report of the Intergovernmental Panel on Climate Change. Cambridge, United Kingdom and New York: Cambridge University Press, 2013.

Jiang J, Zhou T, Chen X, Zhang L (2020). Future changes in precipitation over Central Asia based on CMIP6 projections. Environ Res Lett 15(5):054009. https://doi:10.1088/1748-9326/ab7d03

Jiang Z, Li W, Xu J, Li L (2015). Extreme precipitation indices over China in CMIP5 models. Part I: Model evaluation. J Climate 28(21):8603-8619. https://doi.org/10.1175/JCLI-D-15-0099.1

Kang Y, Tang H, Zhang L, Wang S, Wang X, Chen Z, Zheng C, Yang Y, Wang Z, Huang G, Gao R (2021). Long- 
term temperature variability and the incidence of cardiovascular diseases: a large, representative cohort study in China. Environ Pollut. 116831. https://doi:10.1016/j.envpol.2021.116831

Krishnan A, Bhaskaran PK (2020). Skill assessment of global climate model wind speed from CMIP5 and CMIP6 and evaluation of projections for the Bay of Bengal. Clim Dynam 55(9):2667-2687. https://doi.org/10.1007/s00382-020-05406-Z

Kim YH, Min SK, Zhang X, Sillmann J, Sandstad M (2020). Evaluation of the CMIP6 multi-model ensemble for climate extreme indices. Weather Clim Extreme 29:100269. https://doi:10.1016/j.wace.2020.100269

Kim MK, Yu DG, Oh JS, Byun YH, Boo KO, Chung IU, Park JS, Min SK, Sung HM (2020). Performance Evaluation of CMIP5 and CMIP6 Models on Heatwaves in Korea and Associated Teleconnection Patterns. J Geophys Res-Atmos. 125(23):e2020JD032583. https://doi.org/10.1029/2020JD032583

Knutti R (2010). The end of model democracy?. Climatic Change 102:395-404. https://doi:10.1007/s10584-010-9800-2

Lei X, Liu L, Chen R, Liu C, Hong J, Cao L, Lu Y, Dong X, Chen X, Qiu X, Xia M, Ding B, Qian L, Wang L, Zhou W, Gui Y, Kan H, Zhou Y, Zhang X (2020). Temperature changes between neighboring days and childhood asthma: a seasonal analysis in Shanghai, China. Int J Biometeorol, 1-10. https://doi: 10.1007/s00484-02002057-x

Lewis SC, King AD, Perkins-Kirkpatrick SE (2017). Defining a new normal for extremes in a warming world. B Am Meteorol Soc 98(6):1139-1151. https://doi:10.1175/BAMS-D-16-0183.1

Li X, Xu C, Li L, Luo Y, Yang Q, Yang Y (2019). Evaluation of air temperature of the typical river basin in desert area of Northwest China by the CMIP5 models: A case of the Kaidu-Kongqi River Basin. Resources Science 41(6): 1141-1153. https://doi:10.18402/resci.2019.06.13

Li Z, Yan Z (2010). Application of multiple analysis of series for homogenization to Beijing daily temperature series (1960-2006). Adv Atmos Sci 27(4):777-787. https://doi:10.1007/s00376-009-9052-0

Liu Y, Guo Y, Wang C, Li W, Lu J, Shen S, Xia H, He J, Qiu X (2015). Association between temperature change and outpatient visits for respiratory tract infections among children in Guangzhou, China. Int J Env Res Pub He 12(1):439-454. https://doi:10.3390/ijerph120100439

Luo N, Guo Y, Gao Z, Chen K, Chou J (2020). Assessment of CMIP6 and CMIP5 model performance for extreme temperature in China. Atmos Ocean Sci Lett 13(6): 589-597. https://doi:10.1080/16742834.2020.1808430

Lin H, Zhang Y, Xu Y, Xu X, Liu T, Luo Y, Xiao J, Wu W, Ma W (2013). Temperature changes between neighboring days and mortality in summer: a distributed lag non-linear time series analysis. PloS one 8(6):e66403. https://doi:10.1371/journal.pone.0066403

Luan Y, Yu Y, Zheng W (2016). Review of development and application of high resolution global climate system model. Advance in Earth Science 31(3):258-268. https://doi: 10.11867/j.issn.1001-8166.2016.03.0258

McKenna S, Santoso A, Gupta AS, Taschetto AS, Cai W (2020). Indian Ocean Dipole in CMIP5 and CMIP6: characteristics, biases, and links to ENSO. Sci Rep-UK 10(1):1-13. https://doi:10.1038/s41598-020-68268-9 
Mudryk L, Santolaria-Otín M, Krinner G, Ménégoz M, Derksen C, Brutel-Vuilmet C, Brady M, Essery R (2020). Historical Northern Hemisphere snow cover trends and projected changes in the CMIP6 multi-model ensemble. The Cryosphere 14(7):2495-2514. https://doi.org/10.5194/tc-14-2495-2020

Notz D, Community S (2020). Arctic sea ice in CMIP6. Geophys Res Lett 47(10):e2019GL086749. https://doi:10.1029/2019GL086749

Paik S, Min SK, Zhang X, Donat MG, King AD, Sun Q (2020). Determining the anthropogenic greenhouse gas contribution to the observed intensification of extreme precipitation. Geophys Res Lett 47 (12). https://doi.org/10.1029/ 2019GL086875 e2019GL086875

Peng K, Deng J, Zhang Y, Gong Z, Qin B (2019). Short-term temperature fluctuation in the spring in China during 1957-2015. Climatic and Environmental Research, 24 (1):125-134. https://doi:10.3878/j.issn.10069585.2018.17060

Rivera JA, Arnould G (2020). Evaluation of the ability of CMIP6 models to simulate precipitation over Southwestern South America: Climatic features and long-term trends (1901-2014). Atmos Res 241. https://doi.org/104953 10.1016/j.atmosres.2020.104953

Randall D, Khairoutdinov M, Arakawa A, Grabowski W (2003). Breaking the cloud parameterization deadlock. B Am Meteorol Soc 84(11):1547-1564. https://doi:10.1175/BAMS-84-11-1547

Ren G, Chen Y, Zou XK, Zhou YQ, Zhang L (2011). Change in climatic extremes over mainland China based on an integrated extreme climate index. Clim Res 50(1-2):113-124. https://doi:10.3354/cr01023

Schoetter R, Cattiaux J, Douville H (2015). Changes of western European heat wave characteristics projected by the CMIP5 ensemble. Clim Dynam 45(5-6):1601-1616. https://doi:10.1007/s00382-014-2434-8

Seo KH, J Ok (2013). Assessing future changes in the East Asian summer monsoon using CMIP3 models: Results from the best model ensemble. J Climate 26:1807-1817, https://doi:10.1175/JCLI-D-12-00109.1

Sillmann J, Kharin VV, Zhang X, Zwiers FW, Bronaugh D (2013). Climate extremes indices in the CMIP5 multimodel ensemble: Part 1. Model evaluation in the present climate. J Geophys Res-Atmos 118(4):17161733. https://doi:10.1002/jgrd.50203

Shine R, Elphick MJ, (2001). The effect of short-term weather fluctuations on temperatures inside lizard nests, and on the phenotypic traits of hatchling lizard. Biol J Linn Soc 72(4):555-565. https://doi:10.1006/bij1.2000.0516

Shi J, Cui L, Wen K, Tian Z, Wei P, Zhang B (2018). Trends in the consecutive days of temperature and precipitation extremes in China during 1961-2015. Environ Res 161:381-391. https://doi:10.1016/j.envres.2017.11.037

Sui Y, Lang X, Jiang D (2018). Projected signals in climate extremes over China associated with a 2 C global warming under two RCP scenarios. Int J Climatol 38:e678-e697. https://doi:10.1002/joc.5399

Tokarska KB, Stolpe MB, Sippel S, Fischer EM, Smith CJ, Lehner F, Knutti R (2020). Past warming trend constrains future warming in CMIP6 models. Sci Adv 6(12): eaaz9549. https://doi:10.1126/sciadv.aaz9549

Tan ML, Juneng L, Tangang FT, Chung JX, Radin Firdaus RB (2021). Changes in Temperature Extremes and Their Relationship with ENSO in Malaysia from 1985 to 2018. Int J Climatol. https://doi:10.1016/10.1002/joc.6864 
Wang Z, Zhan C, Ning L, Guo H (2020) Evaluation of global terrestrial evapotranspiration in CMIP6 models. Theor Appl Climatol 143:521-531. https://doi.org/10.1007/s00704-020-03437-4

Wang B, Zheng L, Liu DL, Ji F, Clark A, Yu Q (2018). Using multi-model ensembles of CMIP5 global climate models to reproduce observed monthly rainfall and temperature with machine learning methods in Australia. Int J Climatol 38(13):4891-4902. https://doi:10.1002/joc.5705

Wu Y, Miao C, Duan Q, Shen C, Fan X, (2020) Evaluation and projection of daily maximum and minimum temperatures over China using the high-resolution NEX-GDDP dataset. Clim Dynam 55(9):2615-2629. https://doi.org/10.1007/s00382-020-05404-1

Xin X, Wu T, Zhang J, Yao J, Fang Y (2020). Comparison of CMIP6 and CMIP5 simulations of precipitation in China and the East Asian summer monsoon. Int J Climatol 40(15):6423-6440. https://doi: 0.1002/joc.6590

Xu ZW, Hu WB, Tong SL (2014). Temperature variability and childhood pneumonia: an ecological study. Environ Health-Glob 13:51. https://doi:10.1186/1476-069X-13-51

Xu J, Zhao D, Su H, Xie M, Cheng J, Wang X, Li K, Yang H, Wen L, Wang B (2015). Impact of temperature variability on childhood hand, foot and mouth disease in Huainan, China. Public Health 134: 86-94. https://doi.org/10.1016/j.puhe.2015.10.029

Yang T, Tao Y, Li J, Zhu Q, Su Lu, He X, Zhang X (2018). Multi-criterion model ensemble of CMIP5 surface air temperature over China. Theor Appl Climatol 132(3):1057-1072. https://doi:10.1007/s00704-017-2143-4

Yin H, Sun Y, Donat MG (2019). Changes in temperature extremes on the Tibetan Plateau and their attribution. Environ Res Lett 14(12):124015. https://doi.org/10.1088/1748-9326/ab503c

Yuan S, Quiring SM, Leasor ZT (2021). Historical changes in surface soil moisture over the contiguous United States: an assessment of CMIP6. Geophys Res Lett 48(1): e2020GL089991. https://doi.org/10.1029/2020GL089991

You Q, Wu F, Wang H, Jiang Z, Pepin N, Kang S (2020). Projected changes in snow water equivalent over the Tibetan Plateau under global warming of $1.5^{\circ}$ and $2^{\circ}$ C. J Climate 33(12):5141-5154. https://doi:10.1175/JCLID-19-0719.1

Zhao T, Chen L, Ma Z (2014). Simulation of historical and projected climate change in arid and semiarid areas by CMIP5 models. Sci Bull 59: 412-429. https://doi:10.1007/s11434-013-0003-X

Zhan Z, Zhao Y, Pang S, Zhong X, Wu C, Ding Z (2017). Temperature change between neighboring days and mortality in United States: a nationwide study. Sci Total Environ 584:1152-1161. https://doi:10.1016/j.scitotenv.2017.01.177

Zhang Y, You Q, Chen C, Ge J, Adnan, M (2018). Evaluation of Downscaled CMIP5 coupled with VIC Model for Flash Drought simulation in a Humid Subtropical Basin, China. J Clim 31:1075-1090. https://doi.org/10.1175/JCLI-D-17-0378.1

Zhou Tianjun, Zou Liwei, Chen Xiaolong (2019). Commentary on the Coupled Model Intercomparison Project Phase 6 (CMIP6). Climate Change Research 15(5):445-456. https://doi:10.12006/j.issn.1673-1719.2019.193

Zhou X, Wang Q, Yang T (2020). Decreases in days with sudden day-to-day temperature change in the warming world. Global Planet Change 192:103239. https://doi:10.1016/j.gloplacha.2020.103239 
748 Zhu H, Jiang Z, Li J, Li W, Sun C, Li L (2020). Does CMIP6 inspire more confidence in simulating climate extremes over China?. Adv Atmos Sci 37(10):1119-1132.https://doi:10.1007/s00376-020-9289-1

750

751

752

753

754 


\section{Supplementary Files}

This is a list of supplementary files associated with this preprint. Click to download.

- Highlights.docx 